\title{
ESTUDIO
}

\section{¿MÁS SALAS CUNA O PERMISOS POSNATALES MÁS LARGOS? \\ ALTERNATIVAS DE POLÍTICA PARA APOYAR A LA MATERNIDAD Y LA PRIMERA INFANCIA*}

\section{Francisca Dussaillant}

La compatibilización de maternidad y trabajo es uno de los principales problemas a los que se ven enfrentadas las madres. La dirección que ha tomado nuestro país para facilitar esa conciliación de roles, priorizando el acceso a salas cuna por sobre un mejoramiento de la política de permisos posnatales, difiere sin embargo de lo que se está observando en otras sociedades, sobre todo en los países desarrollados.

Este estudio se propone contrastar dos alternativas —un posnatal más prolongado o el acceso universal a salas cuna

Francisca Dussaillant Lehmann. Ph. D. en Economía e Ingeniera Civil Industrial, Universidad Católica de Chile. MA. en Educación, University of North Carolina Chapel Hill. Investigadora del Centro de Estudios Públicos. E-mail: fdussaillantl@cepchile.cl.

* Agradezco a todos quienes a lo largo de esta investigación me propusieron ideas, recomendaron bibliografía o debatieron mis puntos con buenos argumentos. En especial a Harald Beyer, Fernando Coloma, Carolina Corthorn, Rossana Costa, Bárbara Eyzaguirre, Pablo González, María Paz Lagos, Felipe Lecannelier, Carmen le Foulon, Estela Ortiz y Salvador Valdés. Por supuesto, las opiniones aquí vertidas son personales y cualquier error u omisión es de mi sola responsabilidad.

Versión revisada del texto que apareció como Documento de Trabajo $\mathrm{N}^{\circ} 377$, mayo 2009, del CEP.

Estudios Públicos, 115 (invierno 2009). 
para los niños a partir de las doce semanas de vida-, que a su vez son modalidades parcialmente excluyentes entre sí, pues ambas se centran en los niños menores de un año. Se concluye que la evidencia sobre los efectos del cuidado institucionalizado para niños menores de un año dista de ser positiva. Por otro lado, se cuestiona el argumento de que un posnatal más largo perjudica el ingreso de la mujer al mercado laboral, pues esto no aparecería respaldado por la evidencia empírica. Estudios internacionales mostrarían, además, que las madres tienden a considerar más atractivos los mercados laborales que entregan permisos posnatales más prolongados. Asimismo, se señala que en la mayoría de los países en que se han extendido estos permisos ha habido un incremento significativo de la oferta laboral femenina, y que en ocasiones esto se ha traducido en aumentos importantes en el empleo, sobre todo de aquellas mujeres que están en edad de concebir.

Finalmente, se entrega un análisis de costos de distintas alternativas para extender el permiso posnatal. Se sostiene que tales iniciativas no serían especialmente onerosas para el fisco y que, en algunos casos, los costos por madre resultarían inferiores a los costos de sala cuna durante los meses que cubriría la extensión del permiso.

Palabras clave: posnatal; salas cuna; jardín infantil; empleo femenino; políticas de conciliación trabajo-familia.

\section{Introducción}

$\mathrm{L}$ principales problemas a los que se ven enfrentadas las madres que quieren cumplir ambos roles de la mejor manera posible. Para facilitar este proceso, los gobiernos entregan una serie de posibilidades a las mujeres que trabajan, entre las que se encuentran el acceso a centros de cuidado infantil institucionalizado, los permisos posnatales relativamente largos, los subsidios gubernamentales atados al tamaño de la familia, etc.

En este trabajo queremos contrastar dos de estas políticas que, por tener ambas como foco a los niños menores de un año, son (al 
menos parcialmente) excluyentes. Las políticas en cuestión son un posnatal más largo o el acceso universal a salas cuna para los niños a partir de las 12 semanas de vida ${ }^{1}$. Esta última política ha sido ampliamente promovida por el gobierno de Michelle Bachelet a través de su programa Chile Crece Contigo, cuyo foco es el apoyo a la maternidad e infancia en los sectores del $40 \%$ más vulnerable de nuestro país. Por otro lado, una serie de iniciativas legislativas que buscan mejorar las condiciones del pre y posnatal en nuestro país duerme en el Congreso.

A lo largo del artículo iremos descubriendo que la dirección que ha tomado nuestro país en términos de priorización de políticas (dando preferencia al acceso a salas cuna más que a un mejoramiento de la política de posnatal) difiere significativamente de lo que se ha estado observando a nivel internacional, sobre todo en los países desarrollados. Por otro lado, se mostrará que la evidencia sobre los efectos del cuidado institucionalizado para niños menores de un año dista mucho de ser positiva. De hecho, la evidencia de los malos resultados que experiencias prolongadas en salas cuna producen en el desarrollo infantil ha llevado a las naciones industrializadas a fortalecer sus políticas de licencias posnatales y a enfocar sus políticas de educación preescolar hacia niños mayores de uno, incluso mayores de tres o cuatro años.

La evidencia internacional señala que un mercado laboral que entrega permisos posnatales más largos a las madres es percibido por ellas como un mercado atractivo. De esa manera, la mayor parte de las políticas de extensión de estos permisos ha producido un incremento significativo de la oferta laboral femenina que se ha traducido en ocasiones en aumentos importantes en el empleo, en especial de aquellas mujeres que están en edad de concebir. Existe un argumento paralelo que indica que la oferta laboral femenina también aumentaría al ofrecerse acceso gratuito a centros de cuidado infantil. Sin embargo, las mujeres chilenas han declarado en diversas encuestas que no les gusta enviar a sus hijos a estas instituciones, especialmente cuando los niños son muy pequeños. En ese sentido, una política que extienda el período posnatal será percibida por las madres como mucho más afín a sus necesidades reales de compatibilizar el trabajo y la maternidad que la provisión universal de salas cuna.

${ }^{1}$ El final del período posnatal tal como está diseñado hoy en día. 
Es interesante notar que la tendencia internacional en lo que respecta a las políticas de permisos posnatales ha sido la de entregar períodos largos de permisos en los que se abre la posibilidad a los padres de reemplazar a la madre en las labores de cuidado infantil al menos durante alguna fracción del período. De esa manera se incentiva la participación del padre en las responsabilidades de la crianza y se permite a la madre una mayor flexibilidad para aprovechar eventuales oportunidades que se le presenten en el mercado laboral. Aunque las mujeres siguen siendo, en todo el mundo, las principales responsables de la crianza y por ende son las que utilizan en mayor proporción los permisos, abrir estas posibilidades a los padres ha permitido a algunas familias lograr equilibrios que no hubieran sido posibles de no haber existido esta opción.

La discusión que se presenta a continuación no debe entenderse como una renuncia a abordar casos específicos de hogares con disfuncionalidades graves para los que es posible que una sala cuna sea la mejor opción para el niño. Sin embargo, esos casos puntuales deben tratarse como tales y la política pública enfocada a la mayoría de los hogares debiera tener un énfasis diferente en el que se privilegie la permanencia del niño con su madre o su padre. Por otro lado, una política de acceso a centros de cuidado infantil que comience al momento del reintegro de la mujer a su puesto de trabajo es un gran aporte a la empleabilidad de estas madres. Lo fundamental es que ese reintegro se realice ojalá de manera suave (quizá mediante un reintegro inicial a tiempo parcial) y en un momento en que el niño esté preparado para acceder a un ambiente distinto del familiar. La evidencia es categórica en insistir que esas condiciones no se dan antes de que el niño cumpla seis meses o incluso un año de edad.

En vista de la evidencia, se entrega un análisis (inicial) de costos de distintas alternativas de propuestas de extensión del posnatal. Además de mostrar que tales iniciativas no serían especialmente onerosas para el gobierno, se aprecia que en algunos casos al menos los costos por madre son inferiores a los costos que implica la provisión gratuita de salas cuna durante los meses que cubriría la extensión del permiso.

El artículo consta de tres partes: primero se presenta evidencia para nuestro país del efecto de la maternidad en el empleo, la prevalencia en el uso de las salas cuna y jardines infantiles en nuestro país, y las 
necesidades reveladas por las madres en lo que se refiere a permisos posnatales. A continuación se entrega un recuento de la evidencia internacional en lo que concierne a estas dos políticas. Finalmente entregamos un análisis preliminar de costos que contrasta ambos proyectos.

\section{EVIDENCIA EN CHILE}

\subsection{Maternidad y participación laboral}

En nuestro país, al igual que en el resto del mundo, las mujeres con hijos tienen menor participación laboral que las mujeres sin hijos. Mientras menor sea su niño, son más las mujeres que deciden no participar en el mercado del trabajo. El Cuadro $\mathrm{N}^{\circ} 1$ muestra la participación laboral (y empleo) de las mujeres menores de 60 según la edad de sus hijos (cifras para 2006). En el análisis se excluyó a las estudiantes y a las mujeres cuyos hijos no viven con ellas².

El Cuadro $\mathrm{N}^{\circ} 1$ muestra que la presencia de niños pequeños en el hogar es un determinante en la decisión materna de trabajar. La diferencia es notoria: sólo el 34,23\% de las mujeres con hijos menores de un año trabaja, pero más de la mitad (53,66\%) de las mujeres sin hijos menores de dieciocho años lo hace.

La condición de actividad de las madres también varía según el número de hijos menores de una cierta edad que habitan con ella. El Cuadro $\mathrm{N}^{\circ} 2$ muestra la condición de actividad de mujeres según el número de hijos menores de seis años que viven con ellas.

Claramente, los hijos tienen un efecto considerable en la decisión laboral de la madre. Los Cuadros $\mathrm{N}^{\circ} 1 \mathrm{y} \mathrm{N}^{\circ} 2$ nos han confirmado que tanto la edad como el número de niños son determinantes.

Si miramos la experiencia laboral de las mujeres nos encontramos con un panorama similar. El Cuadro $\mathrm{N}^{\circ} 3$ presenta la relación entre experiencia laboral (calculada según las historias laborales de la Encuesta de Protección Social) y el número de hijos. El efecto reportado

${ }^{2}$ Los datos del Cuadro N ${ }^{\circ} 1$ fueron elaborados con la Casen 2006. Se realizó un estudio similar con datos de la Encuesta de Protección Social (EPS) y se obtuvieron resultados cualitativamente similares. En el cuadro, los grupos iniciales son subconjuntos de los posteriores. Por ejemplo, el grupo de madres que califica como "con hijos menores de dos años” necesariamente califica también como "con hijos menores de seis años”. 
CUADRO N ${ }^{\circ}$ 1: SITUACIÓN LABORAL DE MUJERES MENORES DE 60 AÑOS CON Y SIN HIJOS* EN 2006

\begin{tabular}{lccc}
\hline & Empleadas & Desempleadas & Inactivas \\
\hline Todas & 50,99 & 5,26 & 43,75 \\
Con hijos menores de 1 año & 34,23 & 3,36 & 62,41 \\
Con hijos menores de 2 años & 35,65 & 4,63 & 59,71 \\
Con hijos menores de 4 años & 38,46 & 5,29 & 56,25 \\
Con hijos menores de 6 años & 41,46 & 5,66 & 52,87 \\
Con hijos menores de 8 años & 44,50 & 5,34 & 50,17 \\
Con hijos menores de 10 años & 46,07 & 5,39 & 48,54 \\
Con hijos menores de 12 años & 47,08 & 5,24 & 47,68 \\
Con hijos menores de 14 años & 47,75 & 5,14 & 47,11 \\
Con hijos menores de 16 años & 48,64 & 5,03 & 46,33 \\
Con hijos menores de 18 años & 49,04 & 4,93 & 46,03 \\
Sin hijos menores de 18 años & 53,66 & 5,72 & 40,61 \\
\hline
\end{tabular}

* Se consideran "hijos" de una mujer tanto a sus hijos biológicos como a los hijos biológicos de su pareja, cuando éstos habitan con ellos. Se excluye al servicio doméstico puertas adentro.

Fuente: Casen 2006. Se excluye servicio doméstico puertas adentro y estudiantes.

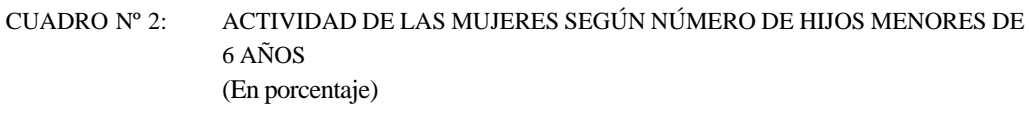

\begin{tabular}{lrrr}
\hline Mujeres & Sin hijos & 1 hijo & 2 o más hijos \\
\hline Ocupadas & 54,07 & 42,52 & 35,27 \\
Desocupadas & 5,13 & 5,81 & 4,78 \\
Inactivas & 40,80 & 51,67 & 59,95 \\
& & & \\
\hline
\end{tabular}

Fuente: Elaboración propia en base a Casen 2006. Se excluye servicio doméstico puertas adentro y estudiantes. $\begin{array}{ll}\text { CUADRO No 3: } & \text { EFECTO DE UN HIJO EN LA EXPERIENCIA LABORAL DE MUJERES Y } \\ & \text { HOMBRES }\end{array}$

Hombres Mujeres

Efecto de cada hijo en la experiencia $\quad 0,75 \quad-1,88$
laboral de su progenitor (años)
$(0,33)$
$(0,29)$

Fuente: Elaboración propia en base a la Encuesta de Protección Social (EPS). Entre paréntesis las desviaciones estándares del estimador. 
indica cuánto afecta cada hijo al número de años de experiencia laboral de padres y madres, controlando por su edad ${ }^{3}$.

La evidencia del Cuadro $\mathrm{N}^{\circ} 3$ nos indica que, para las madres, cada hijo se asocia con una pérdida promedio de casi 1,9 años de experiencia ${ }^{4}$. En cambio para los padres cada hijo representa un incremento en su experiencia laboral de aproximadamente nueve meses. Esto refleja la separación de roles que aún prevalece en nuestra sociedad, donde la madre debe encargarse del cuidado de los hijos mientras el padre cumple un rol de proveedor ${ }^{5}$. Otra explicación para esta diferencia incluye las ventajas comparativas que presenta la mujer en las tareas de crianza y los argumentos sobre la discriminación en el mercado del trabajo que inducirían a las mujeres a tener una mayor presencia relativa en el hogar.

Para completar el análisis podemos indicar las principales razones por las que las madres, según sus declaraciones, deciden no trabajar. Como veremos, las razones de la inactividad femenina en general se asocian con el cuidado de los hijos o con los quehaceres del hogar. El Cuadro $\mathrm{N}^{\circ} 4$ presenta la proporción de mujeres inactivas que declaran alguna de estas dos razones como la principal causa de su decisión de no ingresar al mercado del trabajo.

En suma: frente a la presencia de niños en el hogar, una proporción importante de mujeres elige salir del mercado laboral (o no participar). Esto se debería en parte a que hoy en día no existen suficientes instancias que faciliten a las mujeres armonizar su trabajo con su rol de madres, ya sea a través del acceso a jardines infantiles y salas cuna, de permisos y subsidios maternales suficientemente extensos o de otras políticas asociadas. Este último punto lo vemos confirmado al investigar el comportamiento de las mujeres trabajadoras frente a un embarazo y un parto, que estudiaremos en detalle a continuación.

${ }^{3}$ No se controló por nivel educacional ya que la decisión de fertilidad es endógena a éste. Los coeficientes reportados son meramente descriptivos y no pretenden establecer causalidad. El cuadro presenta los resultados de hacer una regresión simple con experiencia como variable dependiente y edad y número de hijos como variable independiente.

${ }^{4}$ El estimador obtenido para las mujeres corresponde a una cota inferior por dos razones: primero, el cálculo incluye a mujeres cuya suspensión (temporal) de actividades laborales debido a maternidad aún no ha concluido. Además la EPS considera como "ocupadas" a las madres que están haciendo uso de licencias pre y posnatales, con lo que la experiencia efectiva considerada en la estimación está levemente sobrevalorada para éstas.

${ }^{5}$ Esta evidencia no es particular de nuestro país. Aun en economías desarrolladas se observa una mayor prevalencia de inactividad o trabajos part-time en mujeres, y en los países donde existe legalmente un permiso (muchas veces subsidiado parcial o totalmente) para que cualquiera (pero sólo uno) de los padres cuide a su hijo menor de un año, son muy pocos los hombres que lo toman. 
CUADRO No 4 :

RAZONES PARA LA INACTIVIDAD EN MUJERES DE ENTRE 15 Y 59 AÑOS

(En porcentaje)

Cuidado de los niños*

Quehaceres del hogar

Con hijos menores de 6

Con hijos menores de 12

Con hijos menores de 18

Sin hijos menores de 18

Todas
47,52

38,30

30,53

3,53

21,22
32,44

38,36

41,81

43,53

42,41

* Nótese que la opción se refiere al cuidado de niños en general, no necesariamente a hijos de la entrevistada. Por eso observamos que mujeres sin hijos aducen esta razón en alguna proporción.

Fuente: Elaboración propia en base a Casen 2006. Se excluye estudiantes y servicio doméstico puertas adentro.

\subsection{Uso de licencias maternales y licencias por enfermedad del hijo menor de un año}

Jocelyn escribió el 14 de enero de 2009 a las 14.19.22:

busco pediatra que me de mas licencia para poder estar mas tiempo con mi nene

hola ... mi nombre es jocelyn quisiera que me ayudaran ..les cuento mi licecnia posnatal esta por terminar y quiero estar mas tiempo con mi bebe y no he encontrado aun un medico que me de licencia para alrgar mi post natal, eso de las licencias por reflujo ya no las aceptan y mi hijo es completamenete sano ojala me ayuden y recomienden un medico que de licencia y como lo hago para pedirla ..saludos byee. (Sic)

Ana escribió el 14 de enero de 2009 a las 15.24.47:

no la aceptan si son falsas y no las acompañas de un examen radiologico que compruebe el reflujo, mi hijo tiene reflujo grado 3 , lo digo porque por mamas que consiguen licencias falsas nos ponen a todas las madres en el mismo saco siendo que algunas tenemos hijos realmente enfermos (Sic)

Mariana escribió el 24 de enero de 2009 a las 15.10.03:

busca una siquiatra que te de por depresion post parto (Sic).

Fuente: Foro de Salud Infantil en Chile Crece Contigo

http://www.crececontigo.cl/adultos/foros_ver.php?id=2435 (Enero 2009, transcripción textual). 
En esta sección nos dedicaremos a mostrar que el caso de Jocelyn no es único. Mujeres como ella que buscan extender su posnatal mediante licencias engañosas hay muchas en el país, tantas, que su actuar se nota de manera muy clara en las estadísticas agregadas del gasto gubernamental en licencias por incapacidad laboral. Además, mostraremos que las mujeres chilenas que finalmente logran encontrar a ese pediatra que les extienda la licencia fraudulenta tienen un salario superior al del promedio de las madres trabajadoras. Lo anterior ocurre posiblemente porque las mujeres más capacitadas tienen mayor acceso a información y comprensión del sistema, y además cuentan con la posibilidad de elegir (y pagar) al médico que trate a sus hijos, con lo que les es más fácil acceder a alguno que esté dispuesto a extender licencias fraudulentas.

La evidencia de los Cuadros $\mathrm{N}^{\circ} 5$ y $\mathrm{N}^{\circ} 6$ nos muestra la prevalencia de las licencias maternales y de enfermedad del hijo menor de un año en Chile entre 2003 y 2007. Un estudio detenido de estas cifras nos lleva a corroborar el enorme abuso que hoy existe en las licencias por enfermedad grave del hijo menor de un año (LEGHM1). Las cifras muestran que son muchas las mujeres trabajadoras que sienten que el permiso posnatal no es suficiente para cumplir con los requerimientos de su nuevo hijo. Esto las induce (a ellas y a sus médicos tratantes) a recurrir a prácticas engañosas con las cuales se extiende artificialmente el permiso maternal aduciendo (falsamente) una enfermedad grave del niño.

Los datos del Cuadro $\mathrm{N}^{\circ} 5$ representan el total de días pagados por licencias de pre y posnatal y por concepto de LEGHM1 entre 2003 y 2007. El cuadro también incluye información sobre el número de subsidios iniciados en cada uno de esos años. Si consideramos que

CUADRO No 5: DÍAS TOTALES DE SUBSIDIOS PAGADOS Y NÚMERO DE SUBSIDIOS INICIADOS POR CONCEPTOS RELACIONADOS CON LA MATERNIDAD

\begin{tabular}{lccccc}
\hline & \multicolumn{2}{c}{ Pre y posnatal } & & \multicolumn{2}{c}{ Licencia del hijo } \\
\cline { 3 - 3 } \cline { 5 - 6 } Año & Días pagados & Subsidios iniciados & & Días pagados & Subsidios iniciados \\
& & & & \\
2003 & 7.393 .429 & 121.152 & & 3.546 .166 & 129.752 \\
2004 & 7.056 .086 & 117.281 & & 2.848 .919 & 139.041 \\
2005 & 7.331 .884 & 120.750 & & 3.286 .659 & 148.792 \\
2006 & 7.821 .632 & 130.168 & & 3.949 .480 & 162.898 \\
\hline
\end{tabular}

Fuente: Subsecretaría de Seguridad Social: www.suceso.cl 
CUADRO N ${ }^{\circ}$ 6: TASA DE INCAPACIDAD LABORAL POR CONCEPTO DE SUBSIDIO POR ENFERMEDAD GRAVE DEL NIÑO MENOR DE UN AÑO

\begin{tabular}{lccc}
\hline Año & Fonasa & Isapre & Total \\
\hline 1991 & & & \\
1992 & 0,3 & 1,0 & 0,6 \\
1993 & 0,4 & 1,0 & 0,6 \\
1994 & 0,4 & 1,0 & 0,7 \\
1995 & 0,5 & 1,1 & 0,8 \\
1996 & 0,6 & 1,4 & 1,0 \\
1997 & 0,7 & 1,8 & 1,2 \\
1998 & 0,9 & 2,2 & 1,5 \\
1999 & 1,2 & 3,1 & 2,1 \\
2000 & 1,8 & 3,8 & 2,6 \\
2001 & 2,1 & 4,9 & 3,0 \\
2002 & 2,6 & 5,6 & 3,5 \\
Var. $91-02$ (\%) & 2,7 & 6,5 & 3,7 \\
& 697 & 573 & 569 \\
\hline
\end{tabular}

Fuente: Tokman et al. (2004).

cada cotizante embarazada accede a dos licencias (una prenatal y otra posnatal), podemos calcular el número de nacimientos cubiertos cada año. Así, en 2007 nacieron aproximadamente 72.500 hijos de madres cotizantes. También podemos calcular de manera aproximada el promedio de días de duración de los permisos pre y posnatales que en 2007 fue de 115 días $^{6}$.

Lo anterior nos indicaría que en promedio cada niño menor de un año estuvo gravemente enfermo en 2007 por alrededor de 63 días ${ }^{7}$, es decir, ¡más de dos meses! Lo que significa que, en cada momento, el $22,4 \%$ de los niños de entre doce semanas y un año ${ }^{8}$ presenta una enfermedad de carácter grave.

Este dato es inverosímil. Según la Casen 2006 sólo el 20\% de los niños menores de un año reporta que en el último mes sí tuvo un problema de salud, enfermedad o accidente. Eso entrega una cota

${ }^{6}$ Es razonable que el promedio de días sea inferior a 126 (18 semanas), ya que los partos prematuros se pueden adelantar hasta 10 o más semanas (a veces esas madres pierden el prenatal completo), mientras que los partos que se atrasan sólo lo hacen en una o dos semanas.

${ }^{7}$ El cálculo realizado corresponde a una aproximación, ya que algunos niños que nacieron en 2006 tenían menos de un año en 2007 (y por lo tanto el posnatal de la madre es contabilizado el año 2006, mientras que la enfermedad del niño el 2007). Esto sin embargo no debiera afectar mayormente las estimaciones.

${ }^{8} \mathrm{O}$ sea: 63 días sobre 365-84, que corresponde al tiempo en que la madre tiene derecho al subsidio por enfermedad de su hijo menor de un año. 
superior a la prevalencia real de enfermedades graves en infantes, ya que la pregunta en cuestión incluye también a los enfermos leves y a los niños menores de 12 semanas $^{9}$. Además, el 51\% de las LEGHM1 extendidas el 2006 tuvo como causa el reflujo gastroesofágico ${ }^{10}$, lo que contrasta con la tasa de incidencia internacional (para casos graves) de esta enfermedad, que es de sólo 0,3\% (Jung, 2001).

Asimismo, podemos demostrar que las mujeres que recurren a las LEGHM1 provienen desproporcionadamente de los estratos socioeconómicos más altos. Para ello definimos la tasa de incapacidad laboral (TIL) como el número de días de subsidio pagados por cotizante mujer de entre 15 y 44 años de edad.

El Cuadro $\mathrm{N}^{\circ}$ 6, publicado originalmente en Tokman et al. (2004), describe las marcadas diferencias entre Fonasa e Isapre en lo que se refiere a la tasa de incapacidad laboral por concepto de enfermedad grave del hijo menor de un año. Este cuadro nos muestra que las LEGHM1 históricamente se han entregado en mayor proporción a mujeres que cotizan en Isapre. Como es ampliamente sabido, las cotizantes de Isapre provienen principalmente de los estratos socioeconómicos superiores, por lo que podemos concluir que las LEGHM1 se entregan de manera desproporcionada en los sectores más pudientes de la población.

Las mujeres de Isapre pidieron en 1992 más del doble de días de licencia que las de Fonasa, cifra que se mantuvo relativamente constante en el período reportado ${ }^{11}$. Todo esto sugiere que o bien los hijos de las madres cotizantes más ricas se enferman más gravemente ${ }^{12}$, o estas

${ }^{9}$ No es aventurado pensar, además, que alguna proporción de las madres que al momento de ser encuestadas estaban usando una licencia de manera engañosa va a preferir contestar que su hijo estuvo enfermo aun cuando no haya sido así.

${ }^{10}$ Ver Superintendencia de Salud, 2006.

11 Estas cifras no toman en cuenta las diferencias de fertilidad que pudieran existir entre cotizantes de Fonasa e Isapre. Claramente en el grupo más fértil será mayor la probabilidad de tener un hijo gravemente enfermo, por lo que naturalmente las madres de este grupo pedirán más días de licencia que las del grupo menos fértil (sin ser eso indicio de fraude). En todo caso, a menor nivel socioeconómico la fertilidad tiende a incrementarse (un examen preliminar de la Casen 2006 nos indica una fertilidad promedio de 2,1 para las madres del quintil I y 1,5 para las del quintil V, si consideramos a las madres menores de 60 años y sólo a los hijos que habitan con ellas). Por tanto, deberíamos esperar que en ausencia de fraude las integrantes de Fonasa usaran más las LEGHM1 que las cotizantes de Isapre. La realidad descrita en el cuadro corresponde exactamente a lo contrario.

12 Esta opción es poco probable, ya que está ampliamente documentada la relación positiva entre salud infantil y nivel socioeconómico (a mayor nivel socioeconómico, mejor salud) en niños de todas las edades. Ver, por ejemplo, Case et al. (2002). 
madres tienen mayor información sobre las posibilidades que les da el sistema, sumado a un mayor acceso a licencias fraudulentas. Sin embargo, habría una leve convergencia entre los sistemas que estaría indicando que poco a poco la población más desposeída va ganando acceso a las posibilidades (de abuso) que se les presentan con las LEGHM1.

Toda esta evidencia nos conduce a concluir que el uso engañoso de licencias es una costumbre muy extendida, lo que es a todas luces inaceptable. Peor aun, nos encontramos con una costumbre regresiva que favorece desproporcionadamente a las mujeres de mayores ingresos. Esto es inadmisible: la ley maternal debiera beneficiar a todas las trabajadoras por igual o, de presentarse un sesgo, éste debería favorecer a las mujeres de menores recursos. Por otro lado, es importante establecer que el hecho de que tantas mujeres se estén acogiendo a este resquicio es indicativo de que existe una necesidad no cubierta y por lo tanto se hace urgente una reforma a la institucionalidad vigente.

Si volvemos a mirar los Cuadros $\mathrm{N}^{\circ} 5$ y $\mathrm{N}^{\circ} 6$ nos damos cuenta de que al parecer el abuso de las LEGHM1 ha ido aumentando a través del tiempo. Una hipótesis alternativa sería que en el transcurso de los años analizados hubiese ocurrido un gravísimo deterioro general en la salud de los hijos de las cotizantes. Esto contrasta sin embargo con distintos indicadores de morbilidad y mortalidad que muestran una significativa mejoría de la salud infantil en el período. Por ejemplo, la tasa de mortalidad infantil se redujo en 50\% entre 1990 y 2001 (Tokman et al., 2004).

\subsection{Maternidad, trabajo y jardines infantiles}

Una alternativa que tienen las mujeres que buscan armonizar maternidad y trabajo es la de enviar a sus hijos a salas cuna o jardines infantiles. Es por ello que viene al caso revisar quiénes son las personas que hoy en día están enviando a sus hijos a estas instituciones. Para esos efectos, utilizaremos los datos que nos entrega la Casen 2006, reportados en el Cuadro $\mathrm{N}^{\circ} 7$.

El Cuadro $\mathrm{N}^{0} 7$ nos muestra que mientras el $47,6 \%$ de los hijos de madres ${ }^{13}$ ocupadas asiste al jardín infantil, sólo el 28,5\% de los hijos

${ }^{13}$ Se consideró como "madres” tanto a las madres biológicas como a las compañeras del padre biológico, en caso de que los niños vivan con éste. 
CUADRO No 7: $\quad$ ASISTENCIA A JARDÍN INFANTIL SEGÚN ACTIVIDAD DE LAS MADRES (Niños de 0 a 5 años)

\begin{tabular}{lcc}
\hline Madres & \% que asiste & Número de niños que asisten \\
\hline Ocupadas & $47,57 \%$ & \\
Desocupadas & $40,98 \%$ & 234.667 \\
Estudiantes & $39,13 \%$ & 27.521 \\
Inactivas & $28,50 \%$ & 186.726 \\
& & \\
\hline
\end{tabular}

Fuente: Elaboración propia en base a la encuesta Casen 2006.

de las madres inactivas lo hace. Es interesante notar que más de la mitad de los hijos de madres ocupadas no asiste al jardín, y al mismo tiempo cerca de un tercio de los hijos de madres inactivas sí lo hace. De hecho, el 39,3\% del total de los niños que van al jardín infantil son hijos de madres inactivas, y sólo el 49,5\% lo son de madres trabajadoras.

Si buscamos información más actualizada podemos acudir a reportes de la Junji para 2008 en los que se establece que el 55\% de las madres que enviaron a sus hijos a jardín infantil ese año trabajaban ${ }^{14}$.

Si restringimos nuestro análisis a los niños menores de dos años o a los menores de un año (este último es el rango que nos interesa mayormente para nuestro análisis), nos encontramos con que la asistencia a estos centros es mucho menor que la del grupo amplio de los menores de seis años del Cuadro $\mathrm{N}^{\circ} 7$.

El Cuadro $\mathrm{N}^{\circ} 8$ indica que son muy pocas las madres que envían a sus hijos de menos de un año a la sala cuna. Aunque en niños de entre uno y dos años la proporción aumenta en comparación con las cifras globales del Cuadro $\mathrm{N}^{\circ}$ 7, la asistencia es aún bastante menor.

Cabe preguntarse si lo anterior se debe a problemas de acceso y horarios de esos establecimientos o si se debe a una opción de la madre. En la Casen 2006 hay una pregunta que nos sirve para dilucidar esta cuestión. Se pregunta a los familiares de los niños que no asisten a

\footnotetext{
${ }^{14}$ Esta cifra es levemente diferente en su estimación de las anteriores ya que toma como base el número de madres que envían a sus hijos a jardín infantil, mientras que las anteriores se construyeron con base en el número de niños que asisten a estas instituciones. Si suponemos que cada madre envía a un solo niño, ambas coincidirían. Sin embargo la diferencia entre una y otra forma de estimación no debiera ser demasiado importante.
} 
CUADRO No 8: $\quad$ ASISTENCIA A JARDÍN INFANTIL SEGÚN ACTIVIDAD DE LAS MADRES (En porcentaje)

Madres $\quad$ Menores de 1 año $\quad$ Entre 1 y 2 años

\begin{tabular}{lrr} 
Ocupadas & 8,34 & 15,81 \\
Desocupadas & 0,54 & 5,63 \\
Estudiantes & 5,53 & 14,13 \\
Inactivas & 0,56 & 2,71 \\
\hline
\end{tabular}

Fuente: Elaboración propia en base a la encuesta Casen 2006.

jardín infantil o sala cuna por qué no los envían. Las alternativas de respuesta que se entregan pueden agruparse en dos bloques que llamaremos las alternativas de acceso y las alternativas de preferencias. El primer bloque de alternativas, que incluye opciones como "no hay establecimiento cerca”, "por problemas de locomoción”, “por problemas económicos", "no hay matrículas", "no aceptan al niño en el jardín” y "el horario no me acomoda”, corresponde a respuestas que indicarían que existe un interés por enviar al niño a algún establecimiento, pero que esto no ha sido posible debido a dificultades inherentes al sistema. Por otro lado, el segundo bloque corresponde a las alternativas de preferencias ("no es necesario porque lo cuidan en la casa", "no veo la utilidad de que asista a esa edad", "desconfío del cuidado que recibiría”, "se enfermaría mucho”), que reflejan situaciones en las cuales no hay interés por enviar al niño a la sala cuna o al jardín infantil. Tratándose de niños menores de un año ${ }^{15}$, el 92,23\% de las respuestas corresponde a alternativas de preferencias. Cuando sólo consideramos a hijos cuyas madres están trabajando, esa proporción disminuye sólo levemente a 90,16\%. En el caso de los niños de entre uno y dos años las respuestas son en el 88,96\% alternativas de preferencias, fracción que disminuye a $84,7 \%$ cuando se considera sólo a los hijos de madres ocupadas.

Lo anterior nos lleva a concluir de manera bastante categórica que, al menos hoy en día, la mayor parte de las madres de niños menores de dos años prefiere que su hijo sea cuidado en casa y no está interesada en enviarlo a un establecimiento de sala cuna o jardín infan-

${ }^{15}$ Que no asisten a sala cuna. 
til. Esta información se ve confirmada por los resultados de la encuesta Barómetro y Mujer y Trabajo 2008, cuyo universo de interés comprendió a las mujeres inactivas del Gran Santiago. Estas mujeres declaran que una de las razones por las que no trabajan es que no están dispuestas a dejar a sus hijos al cuidado de otra persona (63\%). De hecho, el $54 \%$ de las mujeres con hijos menores de 14 años de la muestra menciona ésa como la principal razón de su inactividad. La creencia de que los niños están siempre mejor con su madre es muy extendida: el $62 \%$ de las mujeres con niños a su cuidado reporta que piensan que su hijo está mejor con ellas que con cualquier otra persona, proporción que aumenta a un $72 \%$ en el estrato socioeconómico bajo. De hecho, sólo un $5 \%$ de estas encuestadas declara que si trabajara y pudiera pagarlo, le gustaría dejar a su hijo en una sala cuna o jardín de calidad que se ajustara a sus necesidades (cerca de la casa, horario compatible). Todo lo anterior es sin perjuicio de que las mujeres que han tenido experiencias previas con jardines Junji o Integra los evalúan muy bien (nota sobre 6 en todos los aspectos analizados).

El Cuadro $\mathrm{N}^{\circ} 9$ muestra la asistencia a jardín infantil o sala cuna de los hijos de madres ocupadas según el tamaño de la empresa en la que ésta trabaja. En Chile, las empresas que tienen más de 20 trabajadoras deben entregar por ley acceso a sala cuna gratuita a los hijos de éstas que tengan menos de dos años. Aunque no tenemos información desagregada por sexo para el tamaño de empresa, podemos suponer que las empresas con más de 50 trabajadores en su gran mayoría cuentan con una planta de más de 20 mujeres. Sin embargo, el Cuadro N 9 nos indica que sólo el 12,2\% de los niños menores de un año cuyas madres trabajan en esas empresas relativamente grandes asiste efectivamente a sala cuna. Lo anterior se puede deber a preferencias de las madres o a comportamientos indebidos de las empresas ${ }^{16}$. Sin embargo, el comportamiento indebido de las empresas debiera repercutir en una baja asistencia a sala cuna de todos los hijos menores de dos años de esas mujeres, sin distinción de edad. El hecho de que se observe más del doble de asistencia en los niños de entre uno y dos años que en los niños de meses es un indicio de que el argumento de las preferencias maternas es correcto. Eso nos lleva a pensar que aun

${ }^{16}$ Por ejemplo, el uso de múltiples razones sociales para evitar aparecer frente al Estado como empleando a más de 20 mujeres, o el ofrecimiento de salas cuna muy alejadas del trayecto de la madre entre hogar y trabajo. 
si hubiera cobertura universal de salas cuna más de la mitad de las madres optaría por no utilizarlas cuando su hijo es menor de un año.

Acotemos aun más nuestro universo de interés y focalicémonos en el grupo objetivo del programa Chile Crece Contigo, es decir en el 40\% más pobre de la población. Si examinamos la distribución de los niños de hasta dos años que asisten a algún establecimiento del tipo jardín infantil o sala cuna, según estatus laboral de la madre, nos encontramos con los datos del Cuadro $\mathrm{N}^{\circ} 10$.

El comportamiento de las madres más pobres (en lo que se refiere a enviar a sus hijos al jardín o sala cuna) difiere bastante del de las más ricas. En el sector más desposeído (quintiles I y II) se observa que más de un tercio de los niños que asisten a sala cuna o jardín infantil tiene madres que no realizan ninguna actividad laboral remunerada ni educativa. Esto se debe probablemente a la gratuidad de estos

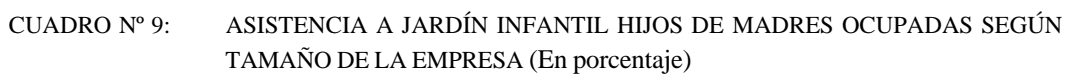
TAMAÑO DE LA EMPRESA (En porcentaje)

\begin{tabular}{lrc}
\hline Empresas & Menores de 1 año & Entre 1 y 2 años \\
\hline Menos de 10 trabajadores & 5,45 & 6,57 \\
10 a 49 trabajadores & 3,66 & 7,60 \\
50 y más trabajadores & 12,42 & 27,12 \\
\hline
\end{tabular}

Fuente: Elaboración propia en base a la encuesta Casen 2006.

\begin{tabular}{lcc} 
CUADRO N ${ }^{\circ}$ 10: & $\begin{array}{l}\text { DISTRIBUCIÓN DE LOS NIÑOS MENORES DE DOS AÑOS QUE ASISTEN AL } \\
\text { JARDÍN INFANTIL O SALA CUNA, SEGÚN ESTATUS OCUPACIONAL DE LA } \\
\\
\text { MADRE (En porcentaje) }\end{array}$ \\
\hline Madres & Quintiles I y II & Quintiles IV y V \\
\hline Madre ocupada & 42,95 & 89,82 \\
Madre desocupada & 4,23 & 0,12 \\
Madre estudiante & 18,99 & 6,68 \\
Madre inactiva & 33,83 & 3,38 \\
Total & 100,00 & 100,00
\end{tabular}

Fuente: Elaboración propia en base a la encuesta Casen 2006. 
establecimientos para este sector socioeconómico. Esos niños podrían perfectamente ser cuidados por sus madres, y, como veremos más adelante, la evidencia indica que con ellas estarían mejor que en los establecimientos a los que asisten. Por otro lado, en los sectores socioeconómicos más altos se observa una mejor distribución de recursos: la mayor parte de los niños que asisten a sala cuna o jardín infantil tiene madres activas.

En suma, el análisis contenido en esta sección nos lleva a concluir que no todas las madres que trabajan envían a sus hijos al jardín infantil o sala cuna y, por otro lado, no todos los niños que van al jardín infantil o sala cuna tienen madres trabajadoras. Este fenómeno se da con mayor intensidad justamente en los grupos de mujeres más pobres, es decir, en el grupo objetivo de las políticas de Chile Crece Contigo. Además, la decisión de no enviar al niño a la sala cuna no se debe necesariamente a problemas de acceso, sino a preferencias de las familias (sobre todo de las familias de los niños más pequeños).

\section{TEORIA Y EVIDENCIA INTERNACIONAL}

\section{1. ¿Por qué los gobiernos deben invertir en el bienestar de los niños?}

En un mundo sin externalidades la solución eficiente de inversión debiera alcanzarse mediante arreglos privados. En el caso de la inversión en infancia, sin embargo, existen varios motivos para pensar que es erróneo confiar en que el mercado nos va a conducir a una solución eficiente.

Un problema que atenta contra la eficiente provisión privada de cuidados infantiles son las restricciones de liquidez: una madre puede querer tomarse un tiempo fuera del trabajo para así mejorar la calidad del desarrollo del niño, pero puede no tener acceso a los medios para mantenerse durante el período en el que no trabaja. Lo mismo sucede con la decisión de mandar al niño a un centro de cuidado de calidad óptima. En un mundo sin restricciones de liquidez los padres podrían pedir prestado ese dinero. Sin embargo, algunos hogares, especialmente los de niveles socioeconómicos inferiores, pueden ver restringido su acceso a este tipo de préstamos. 
Otro argumento es que los padres reducen su inversión en los hijos porque existe incertidumbre sobre el retorno de esa inversión (Lundberg y Pollak, 2007). Al respecto, Lundberg y Pollak destacan que el valor instrumental de los niños para sus padres ha ido cayendo de manera sustancial en el tiempo. Si antes los niños eran fuentes primarias de mano de obra agrícola y de soporte económico en su vejez, la rápida aparición de sustitutos de mercado y gubernamentales ha ido disminuyendo significativamente esos roles.

Incluso si diseñásemos una política que solucionara las restricciones de crédito, hay dos consideraciones más que impedirían que se llegara a la provisión eficiente de cuidado en un mundo puramente privado. Por un lado están las externalidades que este tipo de cuidado impone a la sociedad, y por otro está el altruismo imperfecto.

La inversión en los niños genera externalidades en el sentido de que gran parte del beneficio de la inversión afecta a la sociedad como un todo. Las inversiones en los niños generan externalidades positivas, entre las que se cuentan los retornos a la educación y otras destrezas no cognitivas que contribuyen directamente al stock agregado de capital humano ${ }^{17}$ y a la generación de una red de relaciones en un clima de cohesión social, confianza y reciprocidad que a veces se denomina “capital social” (England y Folbre, 1999, Cleveland y Krashinsky, 2003). En presencia de externalidades, el nivel de inversión al que se llega de manera descentralizada es diferente del óptimo social. Un nivel ineficiente de inversión se traduce en una sociedad menos productiva y con una mayor incidencia de problemas como lo son la delincuencia, drogadicción y embarazo juvenil entre otros.

Otro argumento es el desarrollado por Becker y Murphy (1988), quienes enfatizan que las familias pobres no invierten óptimamente en sus hijos y por tanto argumentan que el gobierno debe intervenir para que estos niños reciban un nivel de inversión eficiente desde un punto de vista social. Según los autores la ineficiencia surge cuando los padres no hacen transferencias (regalos o herencias) a sus hijos. Esto ocurre cuando los individuos son poco altruistas o cuando creen que sus hijos estarán mejor que ellos de todos modos, debido por ejemplo al rápido crecimiento económico. En general, la evidencia sobre transfe-

${ }^{17}$ Una fuente significativa de externalidades de aprendizaje o learning spillovers ver, por ejemplo, en Lucas (1988). 
rencias a los hijos indica que las transacciones eficientes con niños se dan menos en las familias pobres que en las ricas. En ese sentido la intervención estatal, que busca corregir esas ineficiencias, también logrará reducir la desigualdad de oportunidades entre las familias ricas y las familias pobres. Parte del argumento de estos autores se basa en el hecho de que durante la infancia de un niño no es éste quien toma las decisiones que maximizan su bienestar sino que las decisiones son tomadas por los padres. Sin embargo, no todos los padres tienen el mismo altruismo hacia las futuras generaciones y en la mayor parte de los casos el altruismo es imperfecto. Cuando el altruismo es imperfecto, la solución eficiente desde el punto de vista social no se alcanza mediante transacciones privadas y por ende es recomendable algún nivel de intervención gubernamental. Las intervenciones mencionadas por los autores incluyen la obligatoriedad de la educación, pagos del servicio social a familias con niños, reglas estrictas respecto del divorcio cuando hay niños de por medio y edades mínimas para el matrimonio.

Las razones recién esgrimidas parecerían validar la intervención del Estado en el apoyo a la crianza de los niños, en especial de aquellos que nacen en familias de menores recursos. Las opciones de apoyo para los niños de meses son variadas: algunas incluyen el financiamiento directo a la madre para que ésta dedique más tiempo a cuidar al niño, otras consisten en la provisión estatal de servicios de sala cuna y jardín infantil. El objeto de este artículo es justamente definir cuál es la intervención óptima para los niños de menos de un año y sus madres.

\subsection{Permisos parentales}

\subsubsection{Permisos parentales en el mundo}

Frente a un evento de nacimiento o adopción de un niño, en general los distintos países consideran un período de permiso en el cual el trabajo de la madre está protegido y garantizan algún grado de reemplazo salarial para que ésta (y a veces también el padre) cuente con tiempo para adecuarse a los nuevos requerimientos del hogar. Más de cien países, incluyendo virtualmente a todas las naciones industrializadas, han implementado políticas de permisos parentales. 
Muchos países tienen sistemas de protección a la maternidad que consideran dos etapas: la primera, que ocurre inmediatamente después del parto, es un período de recuperación física de la madre y a ésta se la apoya mediante un permiso maternal. En muchas ocasiones, al finalizar el permiso maternal se ofrece un nuevo permiso, el permiso parental, cuyo objetivo es apoyar a la familia en la crianza del niño. En numerosas naciones el permiso parental es intercambiable entre el padre y la madre y en general tiene una duración de varios meses o incluso a veces años. Sin embargo, en vista de que la proporción de hombres que optaban por hacer uso de su derecho era muy menor, varios países han optado por establecer parte de los meses del permiso parental como obligatorios para el padre. Estos permisos los denominaremos permisos paternales. Por otro lado, cuando queramos referirnos en general a todos estos permisos, hablaremos del permiso posnatal. Algunos países tienen una legislación que no distingue entre los distintos permisos: en ellos, el permiso parental comienza al nacer el niño (o incluso antes, en el prenatal), y su objetivo incluye tanto la recuperación física de la madre como el apoyo a la crianza.

La Unión Europea adoptó en 1996 una directiva que establece un mínimo de 14 semanas pagadas (con una "asignación adecuada”) de permiso maternal en los países miembros. Dos de esas semanas deben ser de carácter obligatorio para la madre. Respecto del permiso parental la directiva establece que trabajadores mujeres y hombres deben tener derecho al menos a tres meses de permiso pagado (por tiempo completo o parcial, y de preferencia no transferible entre padre y madre) para cuidar a sus hijos. Este permiso deberá poder tomarse en cualquier momento hasta que el hijo cumpla ocho años. Esta directiva de la Unión Europea sólo establece mínimos, por lo que en la práctica las legislaciones de permisos parentales y maternales difieren mucho entre los distintos países miembros.

Por ejemplo, en los países escandinavos el permiso posnatal tiene una duración de alrededor de un año y existe una "cuota del padre” que reserva un período específicamente al padre para encargarse del cuidado del niño. Dinamarca es el único país de la zona que abolió la cuota del padre en 2002. En estos países la tasa de compensación varía entre un 66\% del salario en Dinamarca y un máximo de $80 \%$ en Suecia, Islandia y Noruega. Otra característica del modelo es la flexibilidad: algunos esquemas permiten el trabajo a tiempo parcial, lo que posibilita a las mujeres 
extender la duración del permiso por un período más largo que si optaran por tomárselo a tiempo completo. Suecia presenta el esquema de permisos más flexible, mientras que en Dinamarca y Finlandia la flexibilidad es menor (Spiess y Whrolich, 2006).

Los otros países de Europa tienen políticas disímiles: Suiza sólo entrega 14 semanas de posnatal con el pago del 80\% del salario de la madre. Francia ofrece hasta tres años de permisos, donde las primeras 16 semanas son pagadas con el $100 \%$ del sueldo materno y el resto del tiempo con asignaciones fijas. Alemania entrega 14 semanas y 14 meses de permiso pagado. Las primeras 14 semanas las madres reciben su salario completo y los 14 meses restantes reciben $2 / 3$ de salario ${ }^{18}$. Otros dos años de permisos no pagados están disponibles para quienes deseen usarlos. En Italia hay un permiso maternal de seis meses con el pago del $80 \%$ del salario materno y a continuación cada uno de los dos padres puede tomarse seis meses (con un máximo de 11 meses por niño). Seis de esos 11 meses son pagados con el 30\% del salario del progenitor que esté tomando el permiso. Irlanda entrega 46 semanas de permiso maternal, 26 de ellas pagadas a una tasa del $80 \%$. A continuación ofrece 14 semanas extraordinarias de permiso no pagado para cada progenitor. Inglaterra ofrece 52 semanas de permiso, de las cuales 39 son pagadas: las primeras seis al $90 \%$ del salario y el resto con una compensación fija.

Respecto a los países no europeos, ni Australia ni Estados Unidos contemplan derechos posnatales pagados, aunque en Australia existe una asignación muy generosa por cada hijo nacido que permite a las madres tomarse parte de su posnatal (de 12 meses sin paga). Por su lado, en Estados Unidos algunos estados, como California, han instaurado algún grado de permiso pagado. En Canadá las distintas provincias tienen diferentes legislaciones pero en promedio se entrega un permiso de 52 semanas, 50 de las cuales son con derecho a pago. Japón entrega 58 semanas, donde las 14 primeras se pagan al 60\% del salario materno y el resto al 30\%. Como incentivo a retomar el trabajo después del posnatal, el Estado paga un bono a los seis meses de retomado el empleo, lo que incrementa la tasa de reemplazo total del sistema japonés hasta un 40\%. En Nueva Zelanda los padres tienen derecho a 56 semanas de permiso, de las cuales dos de ellas las debe tomar el padre

\footnotetext{
${ }^{18}$ Dos de esos catorce meses están reservados específicamente al padre o si no se pierden. El resto pueden tomarlo madre o padre indistintamente.
} 
o se pierden. Las primeras 14 semanas de permiso (algunas de las cuales se pueden tomar en el prenatal) se pagan al $100 \%$ del salario materno, otras 14 con derecho a pago y el resto sin pago.

Ray (2008) resume en detalle las políticas de apoyo a la maternidad vigentes en un importante número de países desarrollados. Las siguientes Figuras $N^{\circ} 1$, 2 y 3 son un resumen de las políticas de permiso posnatal existentes en los distintos países de la OECD. La Figura $\mathrm{N}^{\circ} 1$ muestra los permisos maternales propiamente tales, la $\mathrm{N}^{\circ} 2$ describe los permisos exclusivos del padre y la Figura $\mathrm{N}^{\circ} 3$ el permiso parental que se entrega a continuación del permiso maternal. Las figuras muestran la extensión total del permiso y los pagos que se realizan durante éste. Como en general los distintos permisos son pagados con distintas tasas de reemplazo salarial, una manera de uniformar la medida es calcular los pagos en "equivalentes a trabajo tiempo completo". Esta medida corresponde al número de semanas de salario completo $(100 \%)$ a que equivale el total de los beneficios entregados por el subsidio. Por ejemplo, un permiso de 16 semanas pagadas al $80 \%$ del salario corresponde a un beneficio de 12,8 semanas "equivalentes a trabajo tiempo completo". La Figura $\mathrm{N}^{\mathrm{o}} 1$ utiliza este concepto de manera de facilitar la comparación de la generosidad de los permisos entre países.

\section{FIGURA N ${ }^{\circ}$ 1: $\quad$ PERMISOS MATERNALES}

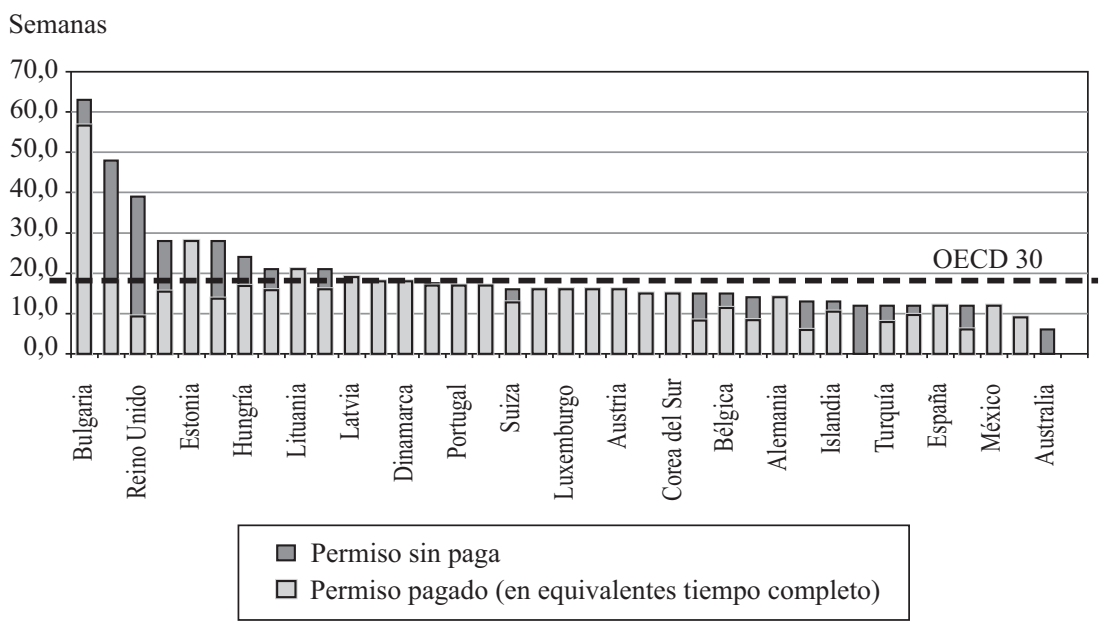

Fuente: OECD Family Database www.oecd.org/els/social/family/database. 
FIGURA N ${ }^{\circ}$ 2: $\quad$ PERMISOS PATERNALES

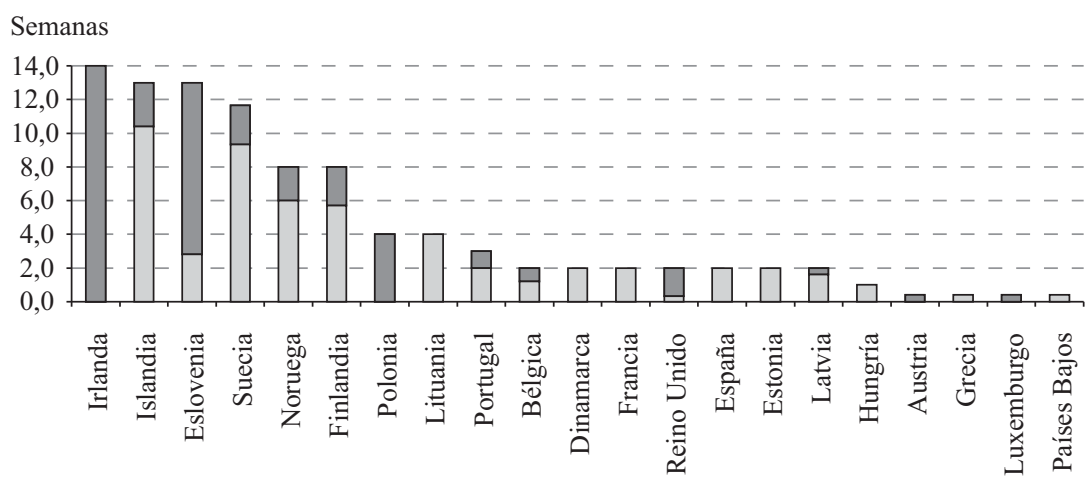

$\square$ Permiso sin paga

$\square$ Permiso pagado (en equivalentes tiempo completo)

Fuente: OECD Family Database www.oecd.org/els/social/family/database.

FIGURA N ${ }^{\circ}$ 3: $\quad$ PERMISOS PARENTALES

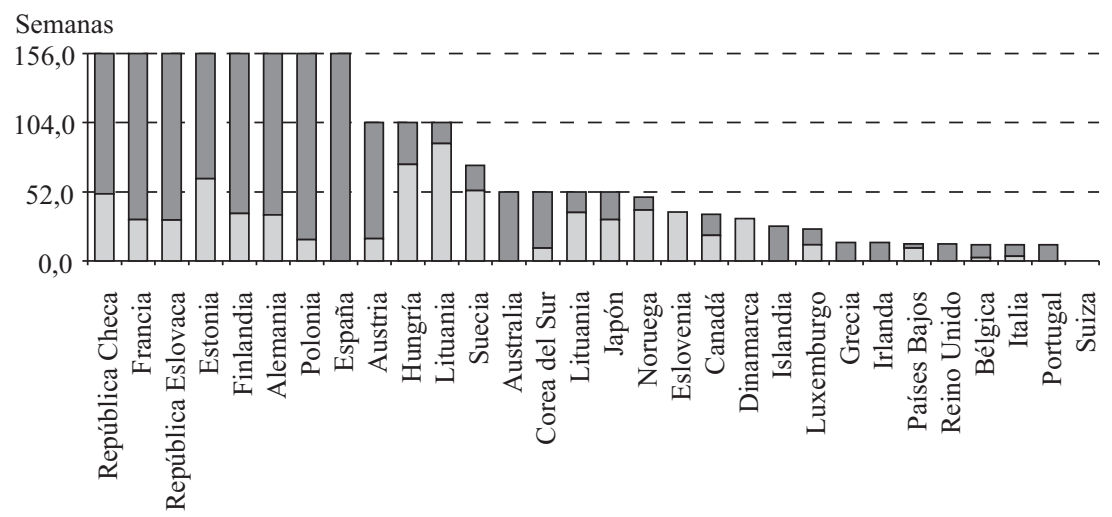

$\square$ Permiso sin paga

$\square$ Permiso pagado (en equivalentes tiempo completo)

Fuente: OECD Family Database www.oecd.org/els/social/family/database. 


\subsubsection{Características de un buen permiso posnatal}

Hay tres características clave que definen un permiso posnatal: los criterios de elegibilidad según los cuales la madre o el padre tiene derecho al permiso, la duración de éste y el nivel de beneficios. En general los permisos son pagados como licencias por enfermedad, o por medio de los seguros de desempleo, sistemas de asignación familiar, beneficios del empleo o como un beneficio aparte de la seguridad social. La principal tendencia de los años 80 y 90 fue la de establecer permisos parentales como suplemento de los permisos maternales ya existentes, generalmente diseñando las políticas de manera tal de incentivar la participación masculina en éstos. La idea detrás de esto último es, además de incentivar la participación de los hombres en labores del hogar, lograr que mujeres y hombres estén en igual pie frente al mercado laboral.

Las diferencias internacionales en lo que se refiere a estas políticas tienen que ver con el objetivo prioritario que se buscaba cuando éstas fueron diseñadas (Kamerman, 2005):

1. apoyar el trabajo en la familia y la crianza de los niños y crear un incentivo para que las mujeres salgan del mercado del trabajo cuando los niños son muy pequeños, o

2. facilitar el trabajo femenino fuera del hogar y al mismo tiempo ayudar a conciliar trabajo y familia mediante la protección y promoción del bienestar de los niños mientras sus padres trabajan, o

3. permitir que mujeres y hombres elijan entre las opciones anteriores según sus propias preferencias.

$\mathrm{Al}$ respecto, existen cuatro pilares esenciales que definen el desempeño de los sistemas:

a) El permiso debe ser pagado: la evidencia indica que cuando los permisos son sin paga, sólo algunas mujeres lo toman, y de manera parcial (ver, por ejemplo, Smolenski y Gootman, 2003, p. 235). En general, la mayor parte de las madres necesita un ingreso familiar, sobre todo cuando su grupo familiar va aumentado. Los pagos, sin embargo, no necesariamente deben reemplazar el $100 \%$ del salario de la madre o del padre. Las tasas de reemplazo comúnmente aplicadas en los países estudiados se encuentran sobre el 50\%, pero bajo el $90 \%$. El 
pago del permiso debe ser de cargo del Estado para no desincentivar la demanda de trabajadoras.

b) Cobertura universal: si el objetivo del permiso es entregar libertad a las madres para decidir si ingresar o no al mercado laboral (opción 3 recién enumerada), y además se origina como un apoyo a la crianza, entonces no hay razón alguna para negar el beneficio a aquellas mujeres que acaban de ser madres pero que no tienen empleo formal. En general los países que presentan cobertura universal ofrecen un beneficio mínimo a prácticamente todas las madres, y un beneficio algo superior (atado al salario) a aquellas que participan en el mercado laboral.

c) Flexibilidad: una política en la que los padres puedan decidir entre variadas opciones, en la que la utilización de los permisos sea voluntaria (con la excepción de un período limitado para que la madre se recupere físicamente del parto) y en la que el trabajo a tiempo parcial sea una posibilidad no castigada es una política que reconoce la enorme heterogeneidad que existe entre las mujeres de un país. La flexibilidad permite que diferentes madres puedan acomodarse de la mejor manera posible para ellas a las nuevas demandas de su vida familiar y laboral. En un estudio comparativo de estas políticas en Dinamarca y Suecia, Pylkkanen y Smith (2004) afirman que los instrumentos suecos tienen un impacto mucho mayor en el comportamiento de las madres que los vigentes en Dinamarca. La explicación de la diferencia entre ambos países radica exclusivamente en la flexibilidad del modelo sueco, ausente en el danés, y en el hecho de que en Suecia se induce en mayor grado a la participación masculina en los permisos, aspecto que retomaremos en el cuarto pilar.

Varios países incluyen altas dosis de flexibilidad en sus políticas de permisos: por ejemplo, en Bélgica cada padre tiene derecho a tres meses de permiso parental que debe usar antes de que el niño cumpla cuatro años. El permiso puede tomarse a tiempo completo, o se puede transformar en seis meses de permiso durante el cual el empleado trabaja medio tiempo, o quince meses en los que se trabaja con una jornada de 80\%. En Luxemburgo, los seis meses de permiso parental pagado se pueden tomar en cualquier momento antes de que el niño cumpla cinco años y puede transformarse en doce meses de permiso durante el cual se trabaja la mitad de la jornada usual. Otros países, entre los que se cuentan Francia, Alemania, Grecia, Noruega, España, 
Países Bajos, Suecia e Irlanda tienen políticas maternales cuyos diseños permiten distintos grados de flexibilidad.

d) Incentivo a la participación del padre: los diseños de políticas que permiten a los padres participar del proceso de crianza de sus hijos tienen varios beneficios. Además de las claras ganancias en términos de creación de vínculos sanos en la familia, tenemos que la participación del padre en el proceso iguala a mujeres y hombres frente a potenciales empleadores, corrigiendo al menos parcialmente la asimetría de costos que percibe un empleador al decidir contratar a alguien de uno u otro sexo. Sin embargo, hay que ser cautos en este punto. Los países que diseñan permisos parentales intercambiables se han encontrado con que los padres, aun pudiendo tomárselos, no lo hacen o lo hacen en una proporción muy menor. Esta proporción se incrementa levemente cuando los permisos no son intercambiables y el tiempo asignado al padre se pierde si éste no lo usa. Sin embargo, ese diseño sólo es aceptable en países donde el permiso para la madre ya es suficientemente largo como para asegurar el bienestar del niño (por ejemplo en Suecia). En general, incluso en los países escandinavos donde se supone que los roles familiares son bastante igualitarios, una amplia fracción de los padres decide no usar su porción del permiso, aunque se ha visto alguna evolución en el último tiempo, sobre todo en aquellos países donde los permisos no son intercambiables.

\subsubsection{Efectos de la política de permisos posnatales}

Las políticas de permisos posnatales tienen diversos efectos en la calidad de vida de los niños y de sus padres. En primer lugar, existen efectos en la salud materna tanto física como mental. Los efectos en la salud del niño tienen diferentes orígenes: por un lado, un posnatal más largo aumenta el período de la lactancia, lo que según algunos autores incidiría positivamente en la salud infantil. Por otro lado, la permanencia en un lugar relativamente aislado (en contraste con una sala cuna) impide que el niño adquiera por contagio las enfermedades que normalmente circulan en el ambiente.

Por otro lado, existen efectos a nivel de la sicología de la madre y del niño que se potencian cuando ellos permanecen unidos por un tiempo mayor. Estos efectos en general tienen que ver con la calidad del vínculo entre madre e hijo y con el apego. En general, se ha demostrado que un 
niño que pasa mayor tiempo con su madre tiene mayor probabilidad de generar un apego seguro, y por otro lado la madre se siente más satisfecha respecto a la calidad de su vínculo con el niño.

Finalmente están los efectos en el mercado del trabajo. Un posnatal naturalmente debiera afectar tanto la oferta como la demanda de trabajo femenino. Asimismo, la teoría y la evidencia demuestran que los salarios de las madres se ven afectados por el diseño de estas políticas. A continuación se entregará un detalle de la evidencia internacional que busca establecer la magnitud de cada uno de los efectos recién mencionados.

\section{a) Permisos parentales y salud materna e infantil}

Existe cierta evidencia de que los permisos posnatales inciden significativamente en la salud materna. Chatterji y Markowitz (2004) asocian los permisos maternales a una mejor salud mental de las madres. Por otro lado, McGovern et al. (1995) sugieren que permisos más largos son positivos para la salud mental, vitalidad y buen funcionamiento de ellas.

Se han hecho muchísimos intentos por evaluar las repercusiones que los permisos maternales más largos tienen en la salud infantil. Basándose en datos para 16 países europeos entre 1969 y 1994, Ruhm (2000a, 2000b) sugiere que mayores períodos de permiso pagado se asocian con menores tasas de mortalidad infantil. Más aún, Ruhm estima que el permiso pagado se asocia con reducciones en la mortalidad mucho más marcadas en la etapa posneonatal —así como en niños de entre uno y cinco años- que en las etapas perinatal o neonatal (Ruhm 2000a). El autor argumenta que este patrón lleva a pensar que la relación encontrada es causal.

Por otro lado, Tanaka (2005) estudia las repercusiones en salud infantil de políticas de permisos posnatales en 18 países de la OECD. Sus datos, que cubren más de dos décadas (1969-2000), actualizan y confirman los resultados de Ruhm (2000a y 2000b). Los indicadores de salud que se analizan son mortalidad infantil, bajo peso al nacer y vacunas. La autora confirma que períodos más largos de permiso pagado se asocian con reducciones en la mortalidad infantil mientras que los permisos sin paga no tienen repercusiones significativas. Winegarden y Bracy (1995) también encuentran evidencia de menor mortalidad infantil con permisos maternales más largos. 
La hipótesis detrás de esta relación es que permisos más largos pueden provocar una mayor duración de la lactancia materna, además de una mayor inversión materna en el cuidado del niño. También se argumenta que la salud mejora al estar el niño alejado de centros de cuidado infantil donde los contagios se facilitan.

La investigación en general ha confirmado que las mujeres tienen una mayor probabilidad de suspender la lactancia durante el mes en el que vuelven a trabajar. De hecho, la vuelta al trabajo es una de las principales razones para finalizar la lactancia. Las mujeres que pueden volver al trabajo de manera parcial, o que están en lugares de trabajo más flexibles y apoyadores, pueden mantener la lactancia por mayor tiempo (Lindberg 1996).

Baker y Milligan (2008a) investigan los efectos del empleo materno y de los permisos maternales en la lactancia y la salud infantil. Para ello estudian el impacto de una extensión del permiso maternal en Canadá desde seis meses hasta alrededor de un año en la mayor parte de las provincias. Los autores observan un aumento significativo de la duración de la lactancia y de la lactancia exclusiva durante el primer año. El porcentaje de mujeres que lograron lactancia exclusiva por seis meses se incrementó entre 7,7 y 9,1 puntos. Sus estimaciones son que el período de lactancia aumenta en un tercio de mes por cada mes adicional en que la madre no trabaja, lo que implica una elasticidad de 0,458. Sin embargo, este aumento en la lactancia al parecer no se traduce en una mejora en la salud infantil reportada por los padres.

Por otro lado, Baker y Milligan (2005) no encuentran evidencia de efectos en la salud infantil medida según tasas de mortalidad o incidencia de nacimientos con bajo peso. En otro estudio, los autores no encuentran efectos del aumento de permisos maternales en medidas de desarrollo infantil (Baker y Milligan, 2008b). De la misma manera, Dustmann y Schönberg (2008) no hallan efectos de largo plazo en el desempeño infantil (años de escolaridad, salarios y desempleo a los 25 años) como producto de extensiones del posnatal en Alemania.

\section{b) Empleo materno y calidad de la crianza}

La investigación que liga las repercusiones del empleo materno en el desarrollo infantil es bastante compleja. Clark et al. (1997) subrayan que el principal determinante de un mejor desarrollo del niño es la 
calidad de las interacciones con su madre. Y la calidad de esas interacciones está afectada a su vez por características individuales del niño y la madre, por la calidad de la relación de pareja y el apoyo del padre, y por una mezcla de factores de tensión y factores protectores que inciden en la salud mental de la madre. La vuelta temprana a trabajar es uno de esos factores que interactúan con una serie de otros. Por ejemplo, los autores documentan que madres más depresivas o que pensaban que su hijo tenía un temperamento difícil, y que tomaron permisos más cortos, eran menos positivas, sensibles y receptivas con su hijo.

Smolensky y Gootman (2003), luego de analizar gran parte de la evidencia disponible del efecto del empleo materno en la calidad de las interacciones con los hijos, acotan que las diferencias que se han encontrado entre niños con madres trabajadoras o no trabajadoras se restringen en general a subgrupos específicos de la población (definidos por edades de los niños, sexo y nivel socioeconómico). Hoffman et al. (1999) advierten que existe al parecer un patrón según el cual el empleo materno puede estar asociado con dificultades cognitivas y de desarrollo infantil cuando la madre vuelve a trabajar durante el primer año de vida del niño y lo hace en una jornada extendida (y no a medio tiempo). Estudios posteriores que confirmarían este patrón incluyen a Brooks-Gunn et al. (2002), Han et al. (2001) y Waldfogel et al. (2002). El argumento para explicar este patrón es que un aspecto clave de la calidad de la crianza en el período en cuestión tiene que ver con la sensibilidad materna que puede verse afectada cuando el empleo es muy extensivo y se da muy temprano en la vida del hijo. Es posible que al salir tan temprano a trabajar la madre no haya tenido el tiempo suficiente para aprender las señales que le entrega el niño y no haya desarrollado aún una estrategia consistente de respuesta a esas señales.

Ruhm (2004) comenta que se ha ido creando cierto consenso al respecto: el trabajo de la madre tendría efectos negativos durante el primer año de vida del niño, aunque positivos en el segundo y tercero: "Una conclusión habitual de los análisis más recientes (realizados generalmente con mucho cuidado) es que el trabajo de la madre durante el primer año de vida del niño tiene un impacto nocivo [...], pero cuando el niño tiene dos o tres años, a menudo no se advierten efectos o beneficios contraproducentes del trabajo materno”, Ruhm (2004, p. 157). Sin embargo, el autor no está de acuerdo con esa conclusión y 
sostiene que los efectos negativos del empleo materno, aunque pequeños, se producen durante los tres primeros años de vida del niño.

Un reciente trabajo de Liu y Nördstrom (2009) documenta que el posnatal —al permitir que el niño esté más tiempo con su madreincide positivamente en el desempeño escolar, medido a los 16 años, de los hijos de las madres más educadas. En otras palabras, la interacción entre posnatal y educación materna tiene un efecto positivo en el desempeño escolar del niño, indicando que la política en cuestión serviría como un amplificador del efecto de la educación de la madre en el desempeño del hijo (efecto ampliamente documentado en la literatura). Estos resultados están muy en línea con los encontrados por Bernal (2008). La autora documenta que cada año de los primeros cinco años de vida del niño en que la madre trabaja tiempo completo se asocia con una pérdida promedio de $1 \%$ en los tests cognitivos de éste. Si además el niño ha recibido durante ese período algún tipo de cuidado no materno el efecto negativo se incrementa en $0,8 \%$. Los efectos son mayores en niños con alto nivel de habilidades. En otras palabras, el tiempo que pasan las madres con los niños genera un mayor retorno. En otro estudio Bernal y Keane (2009) confirman que el valor del tiempo materno como insumo en el desarrollo cognitivo del niño es mucho mayor cuanto más educadas sean la madres.

\section{c) Efectos en el mercado del trabajo}

A primera vista podríamos pensar que un posnatal más largo afectaría negativamente la empleabilidad de las mujeres. El argumento que respaldaría esta aseveración es que los empleadores no querrían contratar a estas mujeres que traen consigo una mayor carga de costos en caso de embarazos. Sin embargo, a continuación probaremos que tal análisis es incompleto desde un punto de vista teórico, y además no tiene respaldo alguno en los estudios empíricos.

En general la investigación en el área de los permisos posnatales se ha enfocado en las consecuencias del permiso en el empleo de las madres y en el nivel salarial de las mujeres. La literatura sugiere que no hay consecuencias negativas para empleadores o para las mujeres cuando los permisos considerados son de duración corta o intermedia $^{19}$. Sin embargo, podría haber consecuencias negativas para las

${ }^{19}$ Es decir, permisos cuya duración no exceda los 18 meses. 
mujeres que toman permisos largos (por ejemplo, tres años), particularmente si se toman múltiples permisos de manera secuencial (Ruhm, 1998; Kamerman, 2000).

Desde un punto de vista teórico, un aumento del posnatal debería aumentar la oferta laboral femenina, ya que las mujeres se verían enfrentadas a una regulación más amigable con sus necesidades particulares. Por otro lado, las empresas posiblemente disminuirían su demanda por personal femenino debido al incremento en el costo de estas trabajadoras. Cuando el permiso maternal es financiado por el gobierno, tal incremento de costos es bastante menor y consiste en los costos de búsqueda y la pérdida de productividad ${ }^{20}$ que implica traer un reemplazante a la empresa. En general es esperable, por lo menos en el contexto de una reforma financiada principalmente por el Estado, que el efecto en la demanda sea menor que el efecto en la oferta. Con ello, un aumento del permiso maternal debería aumentar (o, en el peor de los casos, mantener constante) el empleo femenino ${ }^{21}$.

La evidencia empírica respalda este argumento: en general, extensiones del permiso maternal han tenido efectos positivos o neutros

${ }^{20}$ De hecho, es discutible que el costo en productividad sea demasiado alto ya que, aunque posiblemente el reemplazante tenga una productividad menor que la productividad normal de la mujer que está con licencia (debido a mayor conocimiento del funcionamiento del lugar de trabajo y a su capital humano específico), no debemos olvidar que estamos reemplazando a una mujer que acaba de dar a luz. Es muy probable que esa madre, de haberse mantenido en su puesto de trabajo, igualmente hubiese tenido una importante (aunque transitoria) merma en su productividad.

${ }^{21}$ En Chile, los argumentos para sostener que la caída en la demanda sería pequeña o nula, o incluso para sostener que ésta podría aumentar, son varios: primero, una extensión del posnatal que a su vez considere un sistema de desincentivo al fraude por licencias por enfermedad del niño menor de un año (por ejemplo mediante una baja en su cobertura) entregaría al empleador un mayor nivel de certidumbre respecto de la duración del período de ausencia de la mujer que el que hoy existe. Tal incertidumbre es muy costosa para los empleadores. Por otro lado, un posnatal más largo significa una menor carga en costos de sala cuna para los empleadores que tienen en su planta a más de 20 mujeres (éstos deben por ley pagar la sala cuna de los hijos de sus empleadas hasta que cumplan 2 años). Finalmente, el mayor costo en el que incurre el empleador cuando una mujer se embaraza consiste en tener que pagar un sueldo a la mujer durante el año siguiente a que termina el posnatal sin que ésta pueda producir en su total capacidad (debido al cansancio y efectos hormonales del puerperio) y que además no tenga incentivo alguno para ser productiva (debido al fuero). Es el fuero y no el posnatal el que impone principalmente los costos de contratación a las mujeres. Una extensión del posnatal no debería ir acompañada de una extensión del fuero vigente hoy en día. Así, un posnatal más largo implica un período efectivo de fuero con la madre trabajando más corto, lo que es más ventajoso para el empleador que la situación actual. 
en el empleo femenino. Extensiones relativamente $\operatorname{cortas}^{22}$ del posnatal producirían efectos más positivos en la participación laboral femenina que extensiones mayores, como se detallará más adelante.

Es importante también examinar cuáles serían los efectos de una iniciativa de extensión del posnatal en los salarios de las mujeres. Desde un punto de vista teórico, el incremento en la oferta y posible disminución en la demanda que resultaría de este tipo de iniciativas conduce unívocamente a esperar que un aumento en el posnatal incida negativamente en el nivel de salarios femeninos. Sin embargo existe un argumento opuesto que sostiene que un posnatal más extenso favorecería la estabilidad laboral femenina, es decir, disminuiría la probabilidad de que las mujeres se retiraran del mercado al tener un hijo (para regresar unos años después a un trabajo diferente). Esta mayor estabilidad laboral favorece la acumulación de capital humano específico, por lo que las mujeres en trabajos estables deberían ser más productivas y por ende obtener mayores sueldos que las mujeres en trabajos inestables. Con esto se hace posible pensar que un aumento del posnatal lleve a incrementos salariales de las mujeres.

Desde un punto de vista empírico, sin embargo, la evidencia es ambigua. Es posible que los salarios femeninos disminuyan algo al implementarse iniciativas que alargan los permisos maternales, pero también ha habido casos en los que ha ocurrido lo opuesto.

A continuación se presenta un recuento detallado de los estudios que han examinado estas preguntas.

\section{i. Efecto en salarios}

El efecto de los permisos posnatales en los salarios no es claro desde un punto de vista teórico. Cuando el posnatal permite a la mujer mantenerse alejada del trabajo por más tiempo que el que se hubiera tomado de no existir éste, la depreciación de su capital humano conduciría a una disminución salarial. También pueden existir efectos salariales negativos cuando los costos del permiso los debe afrontar el empleador, quien los traspasaría a la mujer en forma de una menor paga. Sin embargo, si el permiso posnatal permite beneficiarse de la posibilidad de mantener el trabajo que se tenía previo al nacimiento, por

${ }^{22}$ Extensiones que no originen un posnatal de más de 12 meses. 
ende manteniendo la experiencia y capital humano específico a éste, los permisos maternales deberían tener un efecto positivo en los salarios.

Hashimoto et al. (2004), en su estudio del sistema norteamericano, detectan efectos pequeños y de corta duración en los salarios femeninos. Después de corregir por heterogeneidad observable y no observable de las mujeres con acceso a permisos posnatales, su estimación establece que estos permisos se relacionarían con un salario $5 \%$ a $10 \%$ superior para las mujeres que tuvieron hijos. Sin embargo estos efectos están concentrados en pocos años posteriores al nacimiento y luego decrecen hasta desaparecer después del quinto año.

Otro estudio que encuentra efectos positivos de los permisos posnatales en los salarios es el de Waldfogel (1998b). El estudio, basado en datos para Estados Unidos e Inglaterra, muestra que las mujeres que tuvieron acceso a permisos incrementaron su salario más que las que no lo tuvieron. La explicación que da la autora para estos resultados es que las mujeres que tienen acceso a los permisos tienen una mayor probabilidad de volver con su antiguo empleador después de que el niño ha nacido, lo que les permite a éstas mantener las buenas combinaciones de puesto-trabajador y continuar su progreso en la firma. Cuando, por otro lado, la mujer se ve forzada a renunciar para cuidar a su hijo, entonces ocurre una pérdida de experiencia, pérdida de buenas combinaciones y la necesidad de comenzar con un nuevo empleador, lo que implica pérdidas salariales importantes.

Por otro lado, también se han documentado esquemas de permisos posnatales generosos que producen efectos negativos en los salarios, especialmente si los permisos son tomados por las madres y no por los padres (ver Nielsen et al., 2004; Datta Gupta y Smith, 2002). Estos esquemas pueden reducir el capital humano de las mujeres en comparación con los hombres y por lo tanto puede surgir algún tipo de efecto de discriminación estadística, que reduzca el crecimiento del salario femenino y por ende aumente la brecha salarial entre hombres y mujeres.

Un estudio empírico de Dinamarca y Suecia (Albrecht et al., 1999) encuentra efectos muy pequeños en los salarios de largo plazo de las madres que tuvieron acceso a permisos maternales. Por otro lado, Ruhm (1998) encuentra evidencia de una disminución salarial para permisos muy extensos. En su estudio sobre Taiwán, Zveglich y Rodgers (2003) encuentran efectos negativos pero no significativos en 
los salarios femeninos. Schönberg y Ludsteck (2007), en un estudio del caso alemán, encuentran efectos salariales negativos para expansiones de los permisos parentales desde 2 a 6 meses, desde 6 a 10 meses y desde 18 a 36 meses.

ii. Efecto en empleo femenino

En general, los permisos posnatales estimulan mayores tasas de participación laboral femenina (Kamerman, 2005). La evidencia empírica que relaciona los permisos posnatales y el empleo femenino en los Estados Unidos es variada. Algunos estudios (Klerman y Leibowitz 1997, 1999; y Baum, 2003) no encuentran una relación significativa mientras otros encuentran un efecto positivo y significativo (Berger y Waldfogel, 2004; Waldfogel, 1998a; Hashimoto et al., 2004).

En su estudio del sistema norteamericano, Hashimoto et al. (2004) detectan repercusiones positivas importantes en la mantención de los puestos de trabajo y en experiencia laboral de las madres después de un nacimiento. Sin embargo, estos efectos son de corta duración: se desvanecen en el largo plazo. No obstante, no hay que perder de vista que el trabajo de Hashimoto et al. estudia los efectos de permisos maternales muy cortos, de doce semanas como máximo y donde las últimas semanas en general no son pagadas.

Waldfogel et al. (1999) comparan a las madres de Estados Unidos, Japón e Inglaterra y descubren que los niños pequeños tienen un efecto muy negativo en el empleo de sus madres. Sin embargo, los autores encuentran evidencia robusta de que una mayor cobertura de permisos parentales aumenta la probabilidad de que una mujer vuelva a trabajar después del nacimiento de un hijo en todos los países estudiados.

En un estudio comparativo de países europeos, Ruhm (1998) encuentra que la legislación de permisos parentales aumenta la tasa de empleo femenino entre 3 y 4\%, e incluso más para mujeres en etapa de tener hijos. Una confirmación de estos resultados para Alemania se encuentra en el estudio de Ondrich et al. (1999)

Baker y Milligan (2005) investigan los efectos de extensiones de los permisos en Canadá. Los autores encuentran que permisos de duración modesta (17 a 18 semanas) no incrementan el tiempo que las madres se quedan en casa (es decir, cuando el permiso era más corto, 
éstas se tomaban más tiempo mediante permisos sin sueldo o simplemente renunciando a su trabajo). Sin embargo, los autores encuentran que estos permisos reducen significativamente el número de mujeres que renuncian a su trabajo al tener un hijo, con lo que aumenta la proporción de mujeres que retornan a su ocupación previa después de haber finalizado el posnatal. Los autores encuentran efectos positivos en el empleo para extensiones más largas de los permisos (a más de 29 semanas). Otro estudio para Canadá (Ten Cate 2000, 2003) encuentra evidencia de un incremento en la oferta laboral femenina en madres de niños de hasta dos años cuando los permisos maternales se alargan. Efectos similares en mujeres en edad de concebir fueron encontrados en Europa por Winegarden y Bracy (1995).

Zveglich y Rodgers (2003) estudian el impacto de las políticas de permisos maternales en Taiwán. Los autores hallaron un impacto positivo de 2,5\% en el empleo femenino. Schönberg y Ludsteck (2007) estudian el caso alemán y encuentran poco impacto en la participación femenina, aunque rechazan la hipótesis de disminución en la oferta.

Los efectos positivos en el empleo desaparecen cuando la extensión del posnatal es extrema. Por ejemplo, al respecto, Spiess y Wrohlich (2006) reportan que la transición alemana desde un posnatal excesivamente largo (tres años) y no demasiado generoso en sus pagos a uno más corto (de catorce meses) pero mejor pagado ha tenido efectos positivos en la participación laboral de madres de niños pequeños. Del Boca et al (2009) encuentran que el empleo femenino está relacionado positivamente con la extensión del permiso, pero luego el efecto comienza a declinar. Ellas estiman un probit bivariado con empleo y fertilidad como variables dependientes. Entre las variables independientes incluyen un indicador del número de meses del permiso, y la misma variable al cuadrado. El efecto en empleo asociado a la variable independiente lineal es importante, positivo y significativo mientras que el efecto asociado al término cuadrático es significativamente negativo pero pequeño. Ese resultado nos indica que el posnatal más largo afecta positivamente el empleo pero el beneficio marginal va disminuyendo según el permiso se va haciendo más largo. El valor de los coeficientes predice que el efecto marginal sería cero para un posnatal de 40 meses (y negativo para posnatales más largos). Sin embargo permisos de 40 meses o más prácticamente no existen en el mundo. Las autoras documentan un efecto pro empleo que es especialmente importante para mujeres sin educación superior. 


\subsection{Salas cuna}

La literatura en general ha enfocado el análisis de los efectos del cuidado infantil institucionalizado en rangos de edad bastante amplios. Sin embargo, existe un cierto consenso en que los efectos de estas instituciones en el comportamiento de los niños difieren según la edad. En general, gran parte de los estudios que reportan beneficios cognitivos importantes en la edad preescolar han evaluado a niños en programas preescolares que comienzan alrededor de los tres años. Estos estudios argumentan que las intervenciones tempranas en niños pequeños en desventaja social son más efectivas que más adelante en su vida. Esto se debe a la naturaleza dinámica del proceso de formación de competencias que corrige desventajas tempranas que serían muy caras de remediar en edades superiores. Según Heckman y Masterov (2007) las intervenciones tempranas reducen el crimen, promueven la graduación escolar, incrementan la entrada a la universidad, reducen la repetición de cursos, los costos en educación especial y previenen embarazos adolescentes. Sin embargo, los autores reconocen que la mayor parte de las intervenciones evaluadas afectaron a niños de prekínder ${ }^{23}$. Hoy en día existe un consenso bastante amplio en que la educación preescolar (a partir de los 3 o 4 años) representa un aporte significativo para la igualación de oportunidades de los niños en desventaja social, consenso con el que concordamos ampliamente.

Como un ejemplo de lo anterior podemos comparar dos intervenciones que han sido vastamente documentadas en la literatura: el proyecto Abecedarian y el proyecto Perry. Ambos consistieron en investigaciones de carácter experimental que han sido latamente analizados en la literatura. Estos proyectos tienen la ventaja de haber sido construidos específicamente con el objeto de investigar los efectos de las intervenciones tempranas en el desempeño de las personas y tienen un diseño experimental que permite contrastar a aquellos que recibieron la intervención con un grupo de control. Ambas intervenciones siguieron a los participantes durante muchos años de manera de establecer si

${ }^{23}$ Con la excepción del proyecto Abecedarian, que recibió niños de en promedio 4,4 años y los trató hasta los 5 u 8 años (según el grupo experimental al que el niño pertenecía). Sin embargo, el diseño de esta intervención, como veremos más adelante, impide reconocer si el efecto final se debe a la intervención en niños menores de un año, o a efectos posteriores. 
los efectos positivos de la asistencia a estos jardines infantiles eran permanentes o se diluían en el tiempo. Sin embargo, ambos proyectos difieren de manera significativa en el tipo de intervención entregada al grupo tratado. El proyecto Abecedarian entregó cuidado el día completo (de 7.30 a 5.30) de lunes a viernes durante 350 días al año a niños de entre cuatro meses y hasta los cinco u ocho años (según el grupo de tratamiento al que se asignó al niño). Por otro lado, el proyecto Perry intervino a niños de 3 y 4 años durante dos horas y media diarias de lunes a viernes a lo largo del año académico (180 días al año). Los costos de la intervención por niño y por año fueron, en el caso de Perry de US\$15.386, dólares de 2002, mientras que los costos del Abecedarian fueron de US\$ 63.476, dólares de 2002, ambos calculados utilizando una tasa de descuento de 3\% (Barnett y Masse, 2007b). Sin embargo, los resultados de ambos en lo que se refiere a beneficios posteriores para los individuos tratados y la sociedad fueron bastante similares $^{24}$, y, más aun, mientras los tratados en el proyecto Perry tuvieron una tasa de criminalidad significativamente inferior a los del respectivo grupo de control, en Abecedarian no hubo diferencia significativa entre tratados y los de control en ese aspecto. Esto lleva a que, finalmente, por cada dólar gastado en el proyecto Perry la sociedad haya ganado 17, mientras que por cada dólar gastado en Abecedarian la sociedad haya ganado 2,5 (Barnett y Masse, 2007b). Como vemos, el proyecto Perry demuestra cuán rentable y beneficioso puede llegar a ser el jardín infantil para niños de tres o cuatro años. El proyecto Abecedarian también aparece como altamente rentable, pero mucho menos que el Perry. Frente a esto surge la pregunta de cuál hubiera sido la rentabilidad de Abecedarian si la intervención hubiese comenzado más tarde en la vida del niño. Es muy posible que tal rentabilidad hubiera aumentado al centrar la intervención en el rango etario en que ésta entrega el mayor beneficio a los niños. De hecho, como veremos más adelante, no está muy claro que enviar a los niños a instituciones de cuidado no materno sea lo más adecuado en la primera infancia (antes de los dos o tres años).

Después del análisis anterior, es fundamental dejar en claro que nuestro interés específico se centra en la evaluación de los efectos que el cuidado institucionalizado tiene en el bienestar y desarrollo de los

${ }^{24}$ Ver, por ejemplo, la tabla 3 de Barnett y Masse, 2007b. 
niños menores de dos años o, acotando aún más, en los niños de meses. Por ende, las conclusiones que de aquí se deriven también son particulares para estas edades y no son extrapolables al tratamiento de niños mayores. De hecho, como veremos a continuación, los efectos de las intervenciones a niños menores de dos años presentan muchas veces efectos opuestos a los documentados para niños mayores de tres.

Algunos de los estudios que se reportan aquí, sin embargo, cubren rangos amplios de edad. El criterio de selección está determinado por el hecho de que la intervención analizada haya incluido a niños de meses, y en general se intentará reportar de manera preferente los resultados para estos niños.

\subsubsection{Salas cuna en el mundo}

El Cuadro $N^{\circ}$ 11, con información extraída de OECD (2006), resume los derechos a sala cuna y jardín infantil que existen en los países de la OECD. Se hace énfasis en los derechos legales según los cuales la provisión del servicio está garantizada por ley y es en general gratuita. Sin embargo, también se comentan otras particularidades de los países en cuestión, incluyendo la existencia de subsidios estatales para servicios no necesariamente garantizados pero ampliamente disponibles, o los casos en que los servicios, a pesar de garantizar el acceso, no son completamente gratuitos.

Se desprende del Cuadro $\mathrm{N}^{\circ} 11$ que la mayor parte de los países de la OECD tiene estatutos legales que garantizan el acceso a algún tipo de educación o servicio de cuidado para niños en edad preescolar. Sin embargo, las garantías en general se dan para niños mayores de tres años. Los países que garantizan el acceso a niños de menor edad (como Suecia, Finlandia y Dinamarca) no lo hacen de manera gratuita sino previo pago del servicio. Países como Australia, Francia y Bélgica y Países Bajos subsidian algunos servicios para niños pequeños, aunque el acceso no está garantizado por ley. Lo anterior revela que la política pública de gran parte de los países desarrollados ha reconocido los beneficios de la educación preescolar como inversión de alto retorno en productividad futura de los niños y también en habilidades no cognitivas. Sin embargo, existe una tendencia generalizada a garantizar el servicio gratuito sólo a partir de edades bastante superiores al año o 
CUADRO N N $^{\circ}$ 11: SERVICIOS DE CUIDADO PARA NIÑOS EN EDAD PREESCOLAR EN LA OECD

País Edad cubierta

por legislación Comentarios

\begin{tabular}{|c|c|c|}
\hline Australia & - & $\begin{array}{l}\text { Generalmente hay acceso disponible a salas cuna gratuitas } \\
\text { para niños de más de un año, pero no hay un derecho } \\
\text { legal involucrado. }\end{array}$ \\
\hline Austria & 3 a 6 & $\begin{array}{l}\text { No hay derecho legal para servicio a los niños menores de } \\
3 \text { años. }\end{array}$ \\
\hline Bélgica & 2,5 a 6 & Existen servicios subsidiados para niños de 0 a 3 años. \\
\hline Canadá & $\begin{array}{l}\text { De } 4 \text { a } 6 \text { (dos } \\
\text { años, prekínder } \\
\text { y kínder) }\end{array}$ & $\begin{array}{l}\text { En Quebec el derecho legal de acceso se estableció para } \\
\text { niños de } 0 \text { a } 6 \text { años pero con un costo para los padres } \\
\text { (aunque subvencionado) }\end{array}$ \\
\hline República Checa & - & $\begin{array}{l}\text { No hay derechos legales pero existe servicio gratuito para los } \\
\text { mayores de tres años. }\end{array}$ \\
\hline Dinamarca & 0,5 a 7 & $\begin{array}{l}\text { 87\% de las municipalidades garantiza el acceso a niños } \\
\text { mayores de un año. Los cursos preescolares son gratuitos } \\
\text { pero los servicios a niños menores requieren de un pago. }\end{array}$ \\
\hline Finlandia & 0 a 7 & $\begin{array}{l}\text { Los servicios son pagados excepto por un año de servicio } \\
\text { preescolar de medio día, que es gratis. }\end{array}$ \\
\hline Francia & 3 a 6 & $\begin{array}{l}\text { No hay derecho legal para niños menores pero hay una } \\
\text { amplia oferta de centros subsidiados que sirven al } 32 \% \text { de } \\
\text { los niños de } 2 \text { años y al } 90 \% \text { de los de } 3 \text { años. }\end{array}$ \\
\hline Alemania & 3 a 6 & No hay derecho legal a servicio para menores de 3 años. \\
\hline Hungría & $\begin{array}{l}3 \text { a } 6 \text { (en la } \\
\text { práctica) }\end{array}$ & $\begin{array}{l}\text { Aunque existe un derecho legal a partir de los } 6 \text { meses, en la } \\
\text { práctica esto no se cumple y el acceso a educación prees- } \\
\text { colar gratuita comienza a los } 3 \text { años de edad del niño. }\end{array}$ \\
\hline Irlanda & 4 a 6 & No existe derecho legal para niños menores de 4 años. \\
\hline Italia & 3 a 6 & No existe derecho legal para menores de 3 años. \\
\hline Corea del Sur & 5 a 6 & $\begin{array}{l}\text { El 20\% de menor ingreso tiene derecho al servicio a partir } \\
\text { de los } 4 \text { años. }\end{array}$ \\
\hline México & 3 a 6 & No existe derecho legal para menores de 3 años \\
\hline Países Bajos & 4 a 6 & Alta inversión en niños en "riesgo" menores de 4 años. \\
\hline Noruega & - & $\begin{array}{l}\text { Sin derechos legales pero en general hay servicio (pagado) } \\
\text { para mayores de } 3 \text {. }\end{array}$ \\
\hline Portugal & 4 a 6 & No existe derecho legal para menores de 3 años. \\
\hline Suecia & 1 a 6 & Gratuito a partir de los 3 años del niño. \\
\hline Gran Bretaña & 3 a 5 & No existe derecho legal para menores de 3 años. \\
\hline Estados Unidos & 5 a 6 & $\begin{array}{l}\text { No existe derecho legal para menores de } 5 \text { años. En } \\
\text { Georgia y Nueva York hay prekínder gratuito. }\end{array}$ \\
\hline
\end{tabular}

Fuente: OECD (2006) en base a información de la Tabla 4.1. 
dos años. El servicio de salas cuna sigue siendo en la mayor parte de los países estudiados una opción no garantizada y en general pagada, ya que no se ha demostrado que el cuidado institucionalizado a niños de tan corta edad sea beneficioso.

\subsubsection{Características de una buena sala cuna}

Existen dos aproximaciones para determinar qué es una sala cuna de calidad. Una está basada en las características estructurales del sistema de cuidado infantil. Estas características incluyen el tamaño del grupo de niños al que se atiende, la razón de cuidadores a niños, el nivel de educación general y especifica ${ }^{25}$ de estos cuidadores, y la estabilidad del contexto, medida por el nivel de rotación que se da en los cuidadores.

La otra forma de medir calidad aplica medidas de cuán adecuado desde un punto de vista del desarrollo infantil es el servicio entregado por el centro. Estas medidas las toman observadores entrenados usando instrumentos estandarizados.

Muchos estudios han encontrado que mientras mayor es el nivel de educación formal y especializada de los cuidadores y mientras mayor es la razón de cuidadores a niños a su cuidado y menor la rotación del personal, mejor la calidad de la experiencia que recibe el niño (Smolensky y Gootman, 2003). Para el rango de edad entre 0 y 12 meses probablemente los indicadores de calidad más relevantes son la razón niño/adulto, el tamaño del grupo y la rotación del personal. Una razón de 3:1 o en el peor de los casos 4:1 es un indicador de un servicio de calidad. Respecto del tamaño del grupo, la recomendación es que éste no supere los seis a ocho niños. A continuación se presentan los estándares de calidad respecto de la razón y tamaño de grupo según tres instituciones relacionadas con el tema del cuidado infantil en Estados Unidos: la National Association for the Education of Young Children (NAEYC), la American Psychological Association (APA) y la American Public Health Association (APHA).

Las recomendaciones del Cuadro $\mathrm{N}^{\circ} 12$ han sido consideradas por varios estados de los Estados Unidos. Por ejemplo, Kansas, Maryland y Massachusetts exigen que las salas cuna cumplan con la razón adulto/

\footnotetext{
${ }^{25}$ Es decir, especializada en educación de niños en su infancia temprana.
} 
CUADRO No 12: RECOMENDACIONES PARA SALAS CUNA Y JARDINES INFANTILES DE CALIDAD

Edad Razón niño/adulto Tamaño máximo de grupo

Recomendaciones NAEYC

$0-12$ meses

$12-24$ meses

24-30 meses

30-36 meses

3-5 años

Recomendaciones APA y APHA

$0-24$ meses

24-30 meses

30-36 meses

3 años

4-5 años

$\begin{array}{rr}4: 1 & 8 \\ 5: 1 & 12 \\ 6: 1 & 12 \\ 7: 1 & 14 \\ 10: 1 & 20\end{array}$

$3: 1$

$4: 1$

$5: 1$

$7: 1$

$8: 1$
8

12

12

14
20

\section{6}

8

10

14

16

Fuente: Jacobson y Barratt (2000).

niño de 1:3 para menores de un año. Maryland también limita el tamaño de grupo a seis y mantiene la razón de 1:3 hasta los 18 meses de edad de los niños, aunque para ese rango etario permite un tamaño de grupo máximo de nueve niños. Otros estados como Connecticut, el distrito de Columbia, Missouri, Dakota del Norte, Oregon, Utah, Vermont, Wisconsin limitan la razón para niños menores de 18 meses a 1:4 con un tamaño máximo de grupo de 8 niños. En especial, el distrito de Columbia y Connecticut mantienen esos límites hasta que los niños cumplen 27 meses (CLASP, 2009).

En vista de lo anterior, los requerimientos que impone el Ministerio de Educación ${ }^{26}$ en Chile (una educadora de párvulos cada cuarenta niños menores de 2 años, y una técnica de educación parvularia cada seis niños, según el Decreto 181 de 2005) dejan bastante que desear ${ }^{27}$.

${ }^{26}$ Que de hecho no se cumplen en todos los establecimientos (ver Dirección de Presupuestos, 2008). Por ejemplo en 2006 el personal que trabajaba en sala de la Fundación Integra estaba conformado en un $94 \%$ por técnicos y un $6 \%$ por educadoras(es) de párvulos. De acuerdo a la relación que está implícita en el D. S. 181/2005 de Educación, dicha proporción debiera ser del orden de 20/80 a 25/75 (20 a 25\% de educadoras y 80 a $75 \%$ de técnicos), dependiendo del nivel parvulario.

${ }^{27}$ De hecho, en la Junji entre los requisitos que se establecen para certificar la calidad de una sala cuna se encuentra un cociente técnico menos estricto: ellos hablan de un educador por 40 niños y un técnico cada 10 en sala cuna. Ver http://www.junji.cl/junjijoomla/index.php?option=com_content\&task=category\&sectionid=24\&id=69\&Itemid=225. 
De hecho, estas reglamentaciones son menos estrictas que las de otros programas que han demostrado malos resultados ${ }^{28}$ en el rango de edad relevante. Los niños menores de un año requieren una atención muy personalizada y por lo tanto son muy caros de atender si se pretende entregarles un cuidado de calidad.

\subsubsection{Efectos de la política de salas cuna}

Desde el punto de vista del bienestar de los niños la evidencia apuntaría a que éstos se encuentran mejor cuando son cuidados por la madre. Esta evidencia proviene de variadas disciplinas: sicología, medicina, economía, entre otras. En general se centra en el hecho de que el niño más pequeño necesita crear un vínculo único y especial con su cuidador, vínculo que es muy difícil se dé en un ambiente institucionalizado donde cada encargado debe cuidar a varios niños a la vez, y donde es bastante probable que la rotación de cuidadores sea alta. Además, si se trata de niños de meses, se han demostrado en numerosas ocasiones los enormes beneficios de la lactancia materna hasta pasados los seis meses de edad. Los estudios referidos a niños de hasta dos años documentan un efecto negativo de la asistencia a salas cuna en el desarrollo infantil, sobre todo en lo que se refiere a habilidades motoras y sociales, salud, depresión materna y satisfacción de la madre con la relación que tiene con su hijo (ver, por ejemplo, Baker et al., 2008), y el desarrollo del lenguaje del niño (Melhuish, 2006).

Es cierto que el ambiente familiar de los niños en desventaja social puede ser de inferior calidad que el de otros niños. Esto implicaría que los niños de familias más pobres enfrentan una mayor probabilidad de vivir en ambientes adversos, con padres ausentes, baja educación y competencias parentales, pocos recursos y falta de esti-

${ }^{28}$ Por ejemplo, el programa de cuidado infantil de acceso universal de Quebec, Canadá, analizado por Baker et al. (2008) (con resultados muy negativos) requiere que al menos dos tercios del staff tengan diploma universitario. Además en Quebec la regulación especifica una ratio máxima de adultos por niños de 1:5 para los menores de 18 meses (OECD, 2004). Por otro lado, en Inglaterra los resultados de evaluaciones del cuidado institucionalizado para niños menores de dos años también fueron negativos (Sylva et al., 2004), lo que llevó a que en ese país se estableciera una razón adulto-niño de 1:3 para los menores de dos años, y se extendiera el permiso maternal pagado a 52 semanas. Los nuevos estándares para la educación preescolar de Inglaterra se encuentran en http:// www.standards.dfes.gov.uk/eyfs/resources/downloads/statutory-framework-update.pdf. 
mulación emocional y cognitiva. Sin embargo, aunque el acceso a jardines infantiles y educación preescolar parece compensar las desventajas de estos niños, la evidencia muestra que, al parecer, la sala cuna no actuaría de la misma manera. Es fundamental evaluar alternativas de educación y apoyo a la maternidad que permitan mejorar el ambiente en el que se crían estos niños de meses. Pero esas intervenciones no deben pasar por separar al niño de su madre sino por apoyar a ésta para que le entregue la mejor calidad de cuidado posible durante su primer año de vida.

A continuación se entrega un resumen de la evidencia recién comentada.

\section{a) Salas cuna, salud y comportamiento infantil y calidad de los vínculos familiares}

En Estados Unidos un estudio de gran escala realizado por el National Institute of Child Health and Human Development (NICHD) investiga los efectos de los distintos tipos de cuidado infantil en el desempeño cognitivo y emocional de los niños. El diseño del estudio ha permitido examinar los efectos de la calidad de los centros, la cantidad de horas por día que el niño pasa fuera de su hogar y el tiempo total que el niño asiste a ellos desde que nace hasta que comienza su educación escolar.

NICHD-ECCRN (2003) reporta que la cantidad de tiempo que el niño ha estado alejado de su madre durante sus primeros cuatro años y medio de vida es un predictor de asertividad, desobediencia y agresividad. Estos efectos sociales negativos son replicados en Belsky (2001), Loeb et al. (2007) y James-Burdumy, Dinarski y Deke (2008). NICHDECCRN (2004) reporta que los efectos negativos en comportamiento recién descritos continúan visibles en niños de primer año básico. Resultados de análisis del proyecto NICHD han llevado a concluir que el efecto del exceso de horas acumulado en estos centros es especialmente negativo cuando parte de las horas de cuidado se han realizado en los primeros seis meses de vida del niño (Smolensky y Gootman, 2003, p. 125). Belsky (2005), en un resumen de la evidencia obtenida en años de investigación del NICHD, sostiene que los niños que han asistido a sala cuna por más de diez horas semanales durante su primer año de vida tienen mayor probabilidad de desarrollar apego inseguro a los 15 y 
36 meses de edad. Los patrones de interacción madre-hijo entre los 3 y 36 meses de edad son relativamente menos armoniosos cuando los niños pasan muchas horas en salas cuna, sin importar la calidad de éstas, aunque el efecto se intensifica cuando la calidad del centro es baja. Sin embargo, Belsky (2005) advierte que la intensidad de los efectos encontrados es relativamente menor: "colocar a los niños por largas horas en un establecimiento de cuidado no materno, de calidad promedio, sí parece estar asociado con algún riesgo (modesto) en el desarrollo, especialmente en lo que se refiere a la relación madre-hijo (hasta primero básico, en el caso de niños blancos), conductas problemáticas (hasta primero básico), competencias sociales y hábitos de trabajo (más allá de tercero básico), y dichos resultados no son meramente producto de centros de cuidado de baja calidad ... [pero] estos efectos no tienen una magnitud particularmente considerable”. Por otro lado, el autor argumenta que el hecho de que hoy en día los servicios de cuidado infantil son cada vez más utilizados y a edades cada vez más tempranas es causa de preocupación, ya que a pesar de que los efectos negativos de estos centros no son de gran magnitud, "pequeños efectos (ya sea positivos o negativos) en muchos niños pueden tener consecuencias mucho más importantes para la sociedad que efectos grandes en sólo algunos”.

Un estudio a gran escala en Gran Bretaña, el Effective Provision of Preschool Education (EPPE) llega a conclusiones muy similares a las del NICHD. Las evaluaciones de este estudio muestran que niveles entre moderados y altos de asistencia a centros de cuidado en niños menores de dos años están asociados con un aumento de los comportamientos antisociales. Resultados similares surgen de un estudio paralelo en Irlanda del Norte (Melhuish et al., 2001; Melhuish et al., 2002a; Melhuish et al., 2002b).

Baker, Gruber y Milligan (2008) estudian un programa universal de subsidios a salas cuna y jardines infantiles en Quebec. Los autores reportan un empeoramiento en habilidades motoras y de desarrollo social de los niños, un aumento en ansiedad, ansiedad de separación e hiperactividad de éstos, un aumento en la depresión materna y una caída significativa en la satisfacción materna respecto a la relación con su hijo. A diferencia del estudio del NICHD, en este estudio los efectos reportados son bastante grandes, en especial para el grupo de 0 a 2 años de edad. Respecto a la salud infantil, los autores reportan un 
empeoramiento generalizado en los niños que asisten a centros de cuidado institucionalizado: encuentran un aumento de más del 200\% en la prevalencia de enfermedades de nariz y garganta, un aumento de más del $80 \%$ en enfermedades de oído, y una caída superior al 55\% en la proporción de niños con excelente salud ${ }^{29}$.

Otro estudio de envergadura en Estados Unidos, el Wisconsin Family and Work Project, muestra que el cuidado institucionalizado de niños cuando se da en sus primeros cuatro meses de vida y por jornadas largas está relacionado con incrementos en la depresión, enojo y ansiedad materna y paterna (Vandell et al. 1997).

Como ya vimos, otro estudio muy citado es el Carolina Abecedarian Project que consistió en una intervención experimental donde participaron 112 niños (entre los que recibieron el tratamiento y el grupo de control), que entraron con una edad promedio de 4,4 meses y fueron evaluados hasta que cumplieron los cinco u ocho años. La calidad del centro que trató al grupo era muy alta, con una razón de adultos a niños de 1:3 para los menores de 2 años y 1:6 para los mayores. Aún se continúa con el seguimiento. A los 21 años los individuos tratados por el Abecedarian habían tenido su primer hijo a una edad superior a la observada en el grupo de control (Ramey et al., 1999). El uso de marihuana también resultó menor entre los individuos tratados. No se encontraron efectos significativos en incidencia de delincuencia o crimen (Barnett, 2008). El problema de este estudio es que, ya que todos los niños recibieron el mismo tratamiento desde 0 hasta 5 años, no es posible determinar si el efecto se produce porque éstos ingresan temprano en su vida a una sala cuna o si son los años posteriores de jardín infantil los determinantes de los buenos resultados. Sin embargo, Barnett y Masse (2007a) indican que los niños del programa Abecedarian eran más agresivos que los del grupo de control, y acotan que esto se contrapone con los resultados de mejor comportamiento de los tratados en intervenciones alternativas que comenzaron a los tres o cuatro años de edad.

Por otro lado, Watamura et al. (2003) encuentran elevados niveles de cortisol (hormona relacionada con el estrés) al final del día en niños que han permanecido toda la jornada en centros de cuidado. Otras investigaciones al respecto (Dettling et al., 1999) han mostrado

${ }^{29}$ Estas estimaciones son de efectos en los tratados. 
que los mayores incrementos en el nivel de cortisol se dan en niños que tienen mayores dificultades en regular sus emociones y comportamiento negativo.

b) Salas cuna y desempeño cognitivo de los niños

Los resultados del Abecedarian muestran una diferencia en coeficiente intelectual (CI) entre los tratados y el grupo de control de 4,5 puntos a los ocho años y 4,6 a los quince años de edad (Campbell y Ramey, 1995). Los niños tratados también tuvieron un mejor desempeño en tareas de lectura y matemáticas a los quince años, y presentaban una menor probabilidad de repitencia y de ser derivados a la enseñanza especial. A los veintiún años los individuos del grupo de los tratados tenían una mayor probabilidad de realizar estudios universitarios (Ramey et al. 1999). Debido al diseño del proyecto Abecedarian, sin embargo, no sabemos si el origen de los efectos está en la intervención a niños de meses o está en la intervención a edades superiores. De hecho, los mismos autores explican: "El diseño no puede evitar confundir la duración (ocho vs. cinco vs. tres años), el momento (timing) (infancia y niñez temprana versus los primeros años de escuela) y los modelos de entrega del tratamiento (enseñanza directa al niño versus actividades en el hogar mediadas por lo padres), de manera que es imposible saber con certeza qué factores son los responsables de la mayor influencia de la educación preescolar en los resultados académicos e intelectuales” (p. 765). Es decir, no sabemos cómo habrían cambiado los efectos si el tratamiento hubiera empezado a los dos o tres años.

Por su parte, estudios del NICHD reportan que los niños que asistieron a centros de cuidado entre las edades de 27 a 54 meses (pero no antes) tienen puntajes en pruebas cognitivas 4,1 puntos por encima de los puntajes de los niños que no asistieron a centros (controlando por aspectos familiares y desempeño previo). La cantidad de tiempo (horas diarias) pasadas en el centro no parece afectar los resultados cognitivos recientemente expuestos (Smolensky y Gootman, 2003, p. 122). Belsky (2005) argumenta que los potenciales beneficios cognitivos y de lenguaje observados en niños que asisten a centros de cuidado infantil están íntimamente relacionados con la calidad del cen- 
tro al que asisten. Es interesante notar además que los beneficios de desarrollo producidos por la asistencia a centros de alta calidad son independientes del tiempo (horas por día) que el niño permanece en éstos, lo que implicaría que, dadas las desventajas emocionales de pasar un mayor tiempo en estas instituciones - desventajas que, como se comentó más arriba, son independientes de la calidad del centro-, no existe argumento alguno que avale la permanencia de estos niños por largas horas en estas instituciones (Belsky, 2008).

En los estudios para Inglaterra, Melhuish (2006) también encuentra que los potenciales efectos cognitivos de la asistencia a centros de cuidado institucionalizados están íntimamente ligados a la calidad del servicio. El autor explica que en el estudio EPPE el grupo que asistió a sala cuna tuvo un menor desarrollo del lenguaje a los 18 meses, y explica que esos resultados se debieron a la baja calidad de las interacciones entre cuidadores y niños a su cargo. Los efectos encontrados por el autor persistieron durante todo el seguimiento que se hizo a los niños (a los tres y seis años).

Como ya se explicó más arriba, un estudio de Raquel Bernal (2008), usando datos del National Longitudinal Survey of Youth (NLSY), documenta que cada año de los primeros cinco años de vida del niño en que la madre trabaja tiempo completo se asocia con una pérdida promedio de $1 \%$ en los tests cognitivos de éste. Si además el niño asiste durante ese período a algún tipo de centro de cuidado no materno (entre los que se cuenta asistencia a una sala cuna o jardín infantil), el efecto negativo se incrementa en $0,8 \%$. Es interesante notar que estos efectos son mayores en el caso de niños con alto nivel de habilidades. En otras palabras, el tiempo que pasan los niños con la madre tiene un mayor retorno (medido por tests cognitivos) en el caso de los niños con mayores habilidades.

En otro estudio de Bernal y Keane (2009), que también usa los datos del NLSY, se investiga el efecto de distintos tipos de cuidado no materno en hijos de madres solteras y se documenta un efecto promedio de ese tipo de servicios de 2,1\% de disminución en la pruebas cognitivas del niño por cada año en que éste concurre a esos servicios. Sin embargo, los autores acotan que existen efectos diferenciados según el tipo de institución de cuidado. En general, sus resultados apun$\tan$ a un efecto muy negativo de los establecimientos de cuidado informal (2,6\% de disminución en pruebas cognitivas) mientras que los 
centros formales no presentarían ningún efecto adverso. Además documentan que los efectos adversos son más patentes en niñas que en niños.

De su revisión de la literatura, Smolensky y Gootman (2003) concluyen que existe alguna evidencia de que más de diez horas semanales de sala cuna en los primeros seis a nueve meses de edad de los niños estarían relacionadas con menores niveles cognitivos en algunos grupos de niños. Según las autoras, no existe aún una explicación clara que revele los procesos o mecanismos que estarían generando estos efectos. Por otro lado, toda vez que se han reportado efectos positivos del cuidado institucionalizado en términos de desempeño cognitivo de los niños, estos efectos están asociados con instituciones de muy alta calidad.

c) Efectos en el mercado del trabajo

Baker, Gruber y Milligan (2008) reportan que el programa universal de subsidios a salas cuna y jardines infantiles instaurado en Quebec en el período 1997-2000 incidió de manera importante en la oferta laboral femenina. El incremento del empleo debido a esta política fue de 7,7 puntos porcentuales, es decir, un aumento de 14,5\% respecto de la participación femenina previa al programa. El aumento en el empleo fue dominado por ocupaciones de jornadas de entre 30 y 40 horas. Efectos similares en oferta laboral femenina debido a la misma política pro familia en Quebec fueron reportados por Lefevre y Merrigan (2008).

Chevalier y Viitanen (2002) encuentran que la disponibilidad de instituciones formales de cuidado infantil aumenta la participación femenina en el mercado del trabajo en el Reino Unido. Otros estudios microeconométricos, especialmente en Estados Unidos, encuentran una elasticidad negativa del empleo, o de la participación femenina en el mercado laboral, a los costos del cuidado de niños. Gelbach (2002), por ejemplo, encuentra que el empleo de madres solteras se incrementa significativamente con la provisión gratuita de kindergartens en el sistema de educación pública. Sin embargo, existen visiones encontradas respecto de la magnitud de los efectos del acceso a cuidado infantil en el empleo o en la participación de las mujeres en el mercado del trabajo. Por ejemplo, los rangos de elasticidades de la participación femenina al 
precio de los servicios de cuidado infantil en Estados Unidos van desde 0,06 hasta $-1,24$, dependiendo del modelo subyacente y la medida de costo utilizada (Jaumotte, 2003). Blau (2000) y Anderson y Levine (2000) comentan que los valores más plausibles para estas elasticidades están en el rango más bajo, es decir, en el orden de - 0,1 y -0,2, hasta un máximo de -0,4. También hay evidencia de que la elasticidad del costo del cuidado infantil cambia con la educación y el ingreso, siendo mayor para mujeres de bajos ingresos y menor capacitación.

En suma, aun cuando hay discrepancias respecto de la magnitud de los efectos, da la impresión de que una política de provisión universal de salas cuna debería incrementar el empleo femenino. Sin embargo, debemos ser cautos: la evidencia recién mostrada se centra en estudios que consideran como cuidado infantil aquel provisto durante todo el período preescolar del niño, por lo tanto no sabemos qué parte del incremento en participación femenina se debe a menores costos de salas cuna para niños menores de un año y qué porcentaje se debe a la disponibilidad de cuidado para niños mayores. En ese sentido, no está claro hasta qué punto esta evidencia sería aplicable a la realidad chilena, en especial a lo que se refiere a la provisión universal (gratuita o subvencionada) de servicios de salas cuna para niños de meses. La existencia de salas cuna abriría la posibilidad de trabajar a mujeres que de otra manera no tendrían alternativa. Sin embargo, como vimos más arriba, da la impresión de que en el caso específico de nuestro país no hay una percepción real de falta de acceso a estos centros, y si algunas mujeres deciden cuidar ellas a sus hijos es más por una opción relacionada con sus preferencias que por falta de acceso.

\subsection{Recomendaciones de política en la literatura y en la experiencia internacional}

Es interesante mostrar las conclusiones a las que han llegado tanto gobiernos, instituciones de nivel mundial como Unicef o investigadores en políticas públicas particulares a la luz de la evidencia que hasta hoy existe sobre políticas de apoyo a la maternidad. A continuación haremos un recuento de las recomendaciones y experiencias de políticas que hemos podido encontrar en la literatura.

En primer lugar, nos referiremos a la posición de la Organización Mundial de la Salud (OMS). Esta organización estableció el año 
2000 que "las mujeres necesitan al menos 16 semanas de permiso después del parto" con el objeto tanto de proteger su salud como la del niño. La OMS también sugiere un prenatal de al menos cuatro semanas de duración.

Un caso muy interesante de mencionar como experiencia genuina de política es la reciente expansión del permiso maternal en Gran Bretaña en 2007 a 52 semanas, 39 de éstas pagadas. Edward Melhuish, uno de los investigadores principales del estudio del EPPE (Effective Provision of Pre School Education) sobre los efectos del cuidado infantil institucionalizado, explica (en comunicación escrita personal) el proceso que se dio en su país y que llevó a una reforma de esa naturaleza. El investigador indica que inicialmente hubo un amplio deseo de que las condiciones del mercado laboral fuesen más adecuadas para las mujeres. Esto llevó a una presión enorme para incrementar el acceso a centros de cuidado infantil, cosa que ha estado ocurriendo en los últimos años en Gran Bretaña. De hecho, en 2004 se estableció en el país la 10-Year Childcare Strategy, una estrategia a diez años plazo para hacer de los servicios de aprendizaje temprano de Gran Bretaña un referente mundial en calidad. Este proceso sigue en marcha y de hecho el número de plazas para niños en edad preescolar se ha duplicado en el país desde 2007.

Sin embargo, el gobierno estaba preocupado por la evidencia recogida por el estudio EPPE que mostraba efectos negativos de las largas horas de cuidado infantil en el apego y que provocaban el comportamiento antisocial de los niños. El estudio EPPE encontró que estos efectos estaban particularmente asociados a altos niveles de cuidado grupal en el primer año de vida del niño. Melhuish argumenta que lo anterior pudo deberse a que la calidad del cuidado ofrecido por las instituciones de su país no era óptima. Sin embargo, asegurar cuidados de alta calidad durante el primer año de vida es más caro que en cualquier otro momento. Lo anterior, junto al hecho de que algunos miembros del gobierno veían al modelo escandinavo como un ideal, hizo que se considerara la posibilidad de extender el permiso posnatal. Melhuish argumenta que el costo de proveer cuidado infantil de alta calidad a niños de meses no es muy diferente e incluso puede superar al costo de las 52 semanas de permiso parental vigente hoy en Gran Bretaña. Este último argumento, junto con los anteriores, llevó al gobierno a decidir que las 52 semanas de permiso se adaptan mejor a las 
necesidades de la madre que trabaja y de su hijo. Con esto, los esfuerzos que aún continúan en ese país por mejorar la calidad y cobertura en jardines infantiles se dirigen ahora a optimizar un servicio diseñado para mayores de un año.

Por su parte, la OECD no ha estado ajena al debate y también ha emitido recomendaciones de política. En vista de la evidencia, OECD (2006) recomienda un permiso posnatal remunerado y flexible de un año. "Al proponer políticas, los gobiernos deben considerar las necesidades reales de las familias contemporáneas, por ejemplo proveyendo y organizando servicios que permitan a los padres un empleo de tiempo completo o parcial según sus deseos. De nuevo, la entrega de permisos parentales remunerados por alrededor de un año, junto al derecho del niño a tener después una plaza en un servicio de cuidado infantil, permite a los padres estar con los niños en el primer año crítico, así como contribuye al presupuesto familiar y facilita el regreso al empleo. Éste es un apoyo humano a la vida y los vínculos familiares que economías industriales avanzadas debieran considerar. La investigación sugiere que un permiso parental de al menos nueve meses produce muchos beneficios: menor mortalidad infantil, mayor lactancia, menor depresión maternal, mayor uso de cuidados de salud preventivos (Chatterji y Markowicz, 2004; Tanaka, 2005). Los permisos no pagados parecen no tener los mismos efectos protectores (Tanaka, 2005). Conectar el final del permiso parental con el derecho a una plaza en un servicio público de cuidado infantil parece ser un elemento crítico de la política de permisos parentales que aumenta considerablemente el bienestar y seguridad de las familias y los infantes” (p. 207).

La Unicef tampoco ha omitido su opinión. En base a la evidencia conocida hasta 2008, sostiene que es preferible que el niño sea cuidado por su madre durante el primer año. "Hoy en día, en consecuencia, la generalización más importante que se puede hacer es que mientras más pequeño es el niño y más largo el tiempo que éste permanece en los servicios de cuidado infantil, mayor es el riesgo. En particular la permanencia por largas horas de los menores de un año en esos servicios es ampliamente considerada como inapropiada. Un cuidado inadecuado en esta etapa, la más crucial de todas, puede traducirse en cimientos débiles y un andamiaje tambaleante para el aprendizaje en el futuro; y lo que es verdad para las destrezas cognitivas y lingüísticas también lo es para el desarrollo sicológico y emocional” (Unicef, 2008, p. 12). Por 
ello, la institución establece una serie de criterios (benchmarks) que debieran ser aplicados al momento de definir una política pública. El primero de éstos dice que "Una condición mínima, una vez que nace el niño, es que uno de sus padres tenga derecho a ausentarse del trabajo por al menos un año (incluido el período de permiso prenatal) recibiendo el 50 por ciento de su salario (sujeto a límites máximos y mínimos). Cuando ambos padres están cesantes o trabajan por cuenta propia, deberían tener derecho a un ingreso no inferior al salario mínimo o al de la asistencia social. $\mathrm{Y}$ al menos dos de las semanas de permiso parental deberían quedar específicamente reservadas para el padre.

Por otro lado, el enorme volumen de conocimiento recogido mediante el estudio del NICHD llevó a Belsky, uno de los investigadores principales a cargo del proyecto, a hacer las siguientes recomendaciones de política: "Los modestos efectos de las salas cuna en el estudio NICHD y otras investigaciones quizás no nos conduzcan directamente a hacer recomendaciones para familias específicas que estén complicadas con las decisiones sobre crianza y cuidado infantil. Sin embargo, desde el punto de vista de la política pública, los resultados del estudio NICHD, junto con los de otros estudios, dan pie para formular las siguientes recomendaciones:

1. que los permisos parentales sean otorgados (y de preferencia sean pagados) por un período similar a los de algunos países escandinavos.

2. que las políticas de impuestos apoyen a las familias que están criando a niños pequeños de manera tal que los padres puedan permitirse hacer los arreglos para la crianza que ellos consideren más apropiados para sus hijos, reduciendo de ese modo la coerción económica que empuja a muchos, en contra de su voluntad, a dejar a los niños al cuidado de otros.

3. que, dado que los servicios de cuidado infantil de calidad alta tienen grandes beneficios, es necesario contar con una mayor disponibilidad de este tipo de establecimientos.

De hecho, todas estas recomendaciones podrían justificarse incluso por razones únicamente humanitarias”.

Jane Waldfogel, otra estudiosa del tema de la maternidad y la infancia desde el área de las políticas públicas, en su libro What Children Need (2006), que recopila el conocimiento que se ha ido adquiriendo durante décadas en lo que se refiere a políticas óptimas para el 
bienestar de los niños, recomienda enfáticamente un posnatal más largo en los Estados Unidos. "La investigación sugiere claramente que por lo menos algunos niños estarían mejor si sus padres pudieran pasar más tiempo en el hogar durante su primer año de vida, ya sea retrasando la vuelta al trabajo o regresando con una jornada parcial. [...] Si como país queremos entregar a nuestros padres la opción de pasar más tiempo en el hogar durante el primer año, la manera más directa de hacerlo es entregando a todos los nuevos padres el derecho a tomarse hasta un año de permiso con fuero. La evidencia indica que para que eso sea efectivo — es decir, para que los padres cambien su conducta— tal permiso deberá ser pagado” (pp. 63-66).

En Chile, Bedregal (2006) realiza una revisión sistemática de estudios relacionados con los efectos que la educación y el cuidado institucionalizado tienen en los niños de hasta cuatro años. Su conclusión, que surge luego de revisar 53 trabajos sobre el tema, es que no resulta claro que la atención o cuidado infantil diurno "tenga un efecto positivo sobre el desarrollo socioemocional. Las evidencias son contradictorias al respecto e incluso parecen ser perjudiciales en niños menores de dos años". Por eso recomienda que "La edad de inicio del cuidado no familiar parece ser entre los dos y tres años. [...] En países europeos y en los Estados Unidos el cuidado infantil otorgado por mayor tiempo y desde más temprana edad se asocia a problemas conductuales y desajuste emocional en grupos de nivel medio y menor riesgo sociodemográfico”. Sus recomendaciones de intervención para el grupo menor de un año indican que "los servicios integrados con énfasis en salud por sobre cuidados en centros parecen ser lo más efectivo, siempre que exista un adulto significativo o padre que se haga cargo del cuidado en el hogar”.

\section{EVALUACIÓN COMPARADA DE LAS POLÍTICAS}

Dada la información recientemente analizada, estamos en condiciones de evaluar, al menos de manera incipiente, las dos alternativas de política mencionadas al principio de este artículo. Las dos opciones serían entonces aumentar el posnatal o facilitar el acceso universal de los niños a salas cuna institucionalizadas. Cada uno de estos proyectos tiene ventajas y desventajas que hay que tener en cuenta al momento de tomar decisiones. A continuación se analizarán varios puntos cruciales. 


\subsection{Focalización}

El objeto de estos proyectos es apoyar especialmente a las madres trabajadoras o estudiantes más pobres. En ese sentido, el análisis de focalización se da en dos frentes: por un lado, quisiéramos que los recursos no se emplearan en beneficiar en demasía a la población menos necesitada, y por otro lado tampoco quisiéramos que se empleasen en la población inactiva ${ }^{30}$. El proyecto de extensión del posnatal está bien evaluado desde el punto de vista de la focalización laboral. Aunque el posnatal beneficia a mujeres de todos los estratos socioeconómicos, es posible manejar la distribución de recursos mediante el establecimiento de topes de remuneración mensual. El proyecto de salas cuna, por otro lado, es más difícil de focalizar desde el punto de vista laboral, ya que la verificación del estado de actividad de la madre es muy costosa. Como vimos anteriormente, son muchas las madres inactivas que envían a sus hijos al jardín infantil mientras una proporción importante de madres activas no lo hace. La focalización hacia el 40\% más pobre de la población es más viable mediante la utilización de la Ficha de Protección Social (suponiendo que ésta refleja de manera fidedigna la condición socioeconómica de la persona).

\subsection{Bienestar de las madres}

Desde el punto de vista laboral da la impresión de que ambos proyectos incrementarán la participación laboral femenina. Aunque la evidencia internacional nos conduciría a pensar que es posible que el proyecto de sala cuna tenga un efecto superior al de posnatal en este aspecto, no debemos olvidarnos de que las madres chilenas no quieren enviar a sus hijos a este tipo de establecimientos, lo que nos induce a pensar que el efecto en participación laboral del proyecto de salas cuna no debiera ser demasiado grande. Además, la creación de empleos de

30 Se podría argumentar que el jardín infantil es un mecanismo "ecualizante” porque a los niños les da una ventaja temprana desde el punto de vista cognitivo. En ese sentido, podría argumentarse que aun cuando la madre esté inactiva es recomendable enviar a los niños a establecimientos de cuidado institucionalizados. Ese argumento puede ser válido para niños mayores de dos años. Sin embargo, el grupo relevante en nuestro análisis es el grupo de niños muy pequeños que no obtendrían ventajas cognitivas reales de asistir a la sala cuna. Para este grupo es muy claro que de estar disponible (inactiva) la madre, la mejor opción es que el niño se quede con ella. 
bajos salarios en este contexto no está justificada económicamente, sobre todo considerando que los hijos de esas madres sufrirán un perjuicio al tener que alejarse de ellas de manera muy temprana. En lo que se refiere a salarios, es posible que los salarios de equilibrio caigan un poco con una extensión del posnatal ${ }^{31}$, lo que no ocurriría con el proyecto de sala cuna.

Ahora bien, el bienestar de las madres no está unívocamente determinado por su participación laboral y su ingreso. Muchas madres valoran la posibilidad de crear un vínculo cercano con su hijo y quieren cuidarlo ellas durante los primeros meses de vida. El abuso de las licencias por enfermedad del hijo menor de un año es evidencia indirecta de esto. En tal sentido, existe una percepción generalizada de que las mujeres quisieran tener un posnatal más largo, aun cuando eso les significara algún nivel de sacrificio salarial. Por otro lado, enviar a los niños pequeños a salas cuna no es una opción demasiado atractiva para gran parte de las mujeres, como lo refleja la pregunta de la Casen 2006 comentada más arriba. Las preferencias más intensas por una política versus la otra son un indicativo cierto de que las mujeres perciben que su bienestar será mayor si se implementa la política que ellas prefieren. En suma, da la impresión de que el bienestar de las mujeres se incrementaría más con una extensión del posnatal que con un proyecto masivo de salas cuna para los menores de un año.

\subsection{Bienestar de los niños}

En general la evidencia apunta a que los niños se sienten siempre mejor en un ambiente en el cual esté presente la madre, o alguien que se preocupe de ellos de manera exclusiva. La evidencia también apunta a que el cuidado institucionalizado para niños menores de dos años tiene efectos negativos en el desarrollo sicomotor de los niños, perjudica su relación con la madre, afecta negativamente su salud y aumenta su ansiedad. En ese sentido, el aumento del posnatal sería la mejor opción desde el punto de vista de los menores, a no ser que el proyecto de salas cuna tenga un nivel de calidad (y consecuentes costos) muy

${ }^{31}$ El efecto "estabilidad laboral” discutido previamente, que debiera empujar los salarios al alza, tendría una influencia menor en nuestro país. Lo anterior se debe a que en Chile el fuero maternal de un año, vigente hoy en día, ya contribuye bastante a la estabilidad laboral de las madres. 
alto, con atención personalizada y un grado de capacitación óptimo del personal a cargo. Este nivel de calidad de servicios de sala cuna no ha sido logrado en países desarrollados como Canadá o Inglaterra. En este último país la dificultad de entregar un servicio de calidad en salas cuna (y los consecuentes efectos adversos observados en los niños) indujo al gobierno a extender el permiso maternal pagado hasta un año.

Es cierto que siempre van a existir, por una u otra razón, casos aislados de madres incapacitadas para atender a sus niños. En estos casos se requiere apoyo externo para garantizar el correcto desarrollo del niño. Sin embargo lo anterior no justifica una política generalizada de salas cuna.

\subsection{Costos para el país}

3.4.1. Costos de una extensión del permiso posnatal

El siguiente análisis nos puede dar una idea aproximada de los costos de esta política.

El Cuadro $\mathrm{N}^{\circ} 13$ nos entrega información sobre el monto de los recursos utilizados por el Estado por concepto de pre y posnatal entre los años 2003 y 2007. Si nos centramos en los datos relativos a 2007, y suponemos que ese año nacieron en Chile alrededor de 72.500 hijos de mujeres cotizantes ${ }^{32}$, podemos calcular el costo promedio anual por

CUADRO N $13: \quad$ RECURSOS* UTILIZADOS EN PAGOS DE LICENCIAS MATERNALES

\begin{tabular}{lcc}
\hline Años & $\begin{array}{c}\text { Pre y posnatal } \\
\text { (M\$ del año) }\end{array}$ & $\begin{array}{c}\text { Licencia del hijo } \\
\text { (M\$ del año) }\end{array}$ \\
\hline & & \\
2003 & 45.382 .911 & 25.211 .161 \\
2005 & 47.286 .794 & 20.531 .066 \\
2006 & 51.112 .870 & 24.347 .081 \\
2007 & 56.954 .461 & 30.028 .568 \\
& 65.682 .103 & 37.908 .520 \\
\hline
\end{tabular}

* Se refiere sólo a subsidios, no incluye cotizaciones a fondo de pensiones o de salud.

Fuente: Subsecretaría de Seguridad Social: www.suseso.cl.

${ }^{32}$ Ese dato surge de un cálculo aproximado a partir de la información contenida en el Cuadro $\mathrm{N}^{\circ}$ 5. Suponemos que cada hijo nacido ese año generó dos licencias: una prenatal y una posnatal. 
madre de las licencias (\$ 905.960). Si consideramos que cada descanso maternal duró ese año alrededor de 115 días, llegamos a un monto diario de \$ 7.878. Con estos datos podemos estimar de manera aproximada el costo de extender el posnatal. Es muy importante enfatizar que el estudio de costos aquí presentado es muy preliminar y aproximado. De hecho, no incluimos en el análisis los ahorros por mayor salud de los lactantes, ni los ahorros por menor utilización de salas cuna, entre otros. Tampoco se estima el costo de permitir que los padres reemplacen a las madres en algunos períodos del posnatal, y suponemos que el nivel de fertilidad no se verá afectado por la política en cuestión ${ }^{33}$. Los cálculos que se realizarán de ahora en adelante se basan en información de licencias del año 2007 y por lo tanto las cifras están expresadas en pesos de ese año. Para transformar las cifras por mujer al costo país de la política se procede como sigue: el costo por mujer se actualiza a marzo de 2009 según IPC, se multiplica por un número de partos aproximado de 72.500 y se convierte la cifra resultante en dólares, considerando un dólar a \$590. Por lo tanto, el costo país reportado está en dólares actualizados a marzo de 2009.

Los cálculos de costos que presentamos aquí son preliminares y aproximados. El cálculo sólo incluye cuánto más (o menos) debería pagar el Estado a cada mujer según distintas posibilidades de extensión del posnatal, considerando el aumento de costos de licencia maternal (conforme al precio por día mencionado más arriba) y la disminución de costos por concepto de menor utilización de licencia por enfermedad del hijo menor de un año. Para esto último usaremos el dato ya mencionado de que alrededor del 65\% de LEGHM1 lo toman madres de niños menores de seis meses. Con eso, cualquier extensión del posnatal a seis meses le significaría al Estado un ahorro de 41 días de LEGHM1 por niño nacido de madre cotizante ${ }^{34}$.

${ }^{33}$ La evidencia sobre el efecto de extensiones del posnatal en la fertilidad es bastante amplia y no se reporta en este trabajo por falta de espacio. Algunos estudios muestran un aumento de la fertilidad causado por esta política (ver por ejemplo Lalive y Zweimüller, 2005), mientras otros no encuentran tales efectos (ver, por ejemplo, Del Boca et al., 2009).

${ }^{34}$ Aunque siempre existe la posibilidad de que parte de estos 41 días se traslade a etapas posteriores. Una forma de minimizar aquello es que a cambio de la extensión del posnatal se reduzca de manera significativa la tasa de reemplazo de la LEGHM1 entre los 6 y 12 meses. 
a) Extensión del posnatal con $100 \%$ de cobertura

- $\quad$ Extensión de 14 semanas (desde las 12 actuales hasta 26 semanas o seis meses): en pesos del 2007, el costo consistiría en el aumento en el pago de licencias pre y posnatales (\$ 7.878*14*7=\$772.044) MENOS el ahorro por menor incidencia de las LEGHM1 $(\$ 8.300 * 41=\$ 340.300)$. Eso da un costo aproximado por madre de $\$ 431.744$, es decir, un costo país de US\$ 58,5 millones anuales.

- $\quad$ Extensión de siete semanas (desde las 12 actuales hasta 19, o un poco menos de cuatro meses y medio): el costo debería ser aproximadamente la mitad del costo de la extensión por 14 semanas, es decir \$215.872 por madre o un costo país de US\$29,3 millones anuales. Es probable que este costo sea incluso menor porque probablemente la distribución de LEGHM1 para niños menores de seis meses está más concentrada en períodos cercanos al final del posnatal de hoy en día. Lamentablemente no tenemos los datos para hacer un cálculo más fino.

- $\quad$ Extensión flexible: siete semanas a tiempo completo, 14 a tiempo parcial o cualquier combinación intermedia (cada una de las semanas a tiempo completo de la extensión puede canjearse por dos semanas a tiempo parcial). Los costos de esta posibilidad son un poco menores que los del caso anterior, ya que disminuye el tiempo efectivo en que la madre puede acceder a las LEGHM1 (una madre que está en posnatal, aun cuando sea de tiempo parcial, no debería tener acceso a este tipo de permisos, a lo más se le debería permitir transformar la jornada de su permiso maternal de manera de adecuarse mejor al cuidado del niño).

b) Extensión del posnatal con $80 \%$ de cobertura (sólo cambia la cobertura de la extensión)

- $\quad$ Extensión de 14 semanas (desde las 12 actuales hasta 26 semanas o seis meses): si suponemos que las LEGHM1 se siguen pagando al $100 \%$, el costo sería de $772.044 * 0,8-340.300$. Eso da un costo aproximado por madre de $\$ 277.335$ o un costo país de US\$ 37,6 millones anuales. 
- $\quad$ Extensión de siete semanas (desde las 12 actuales hasta 19, o un poco menos de cuatro meses y medio): el costo debería ser aproximadamente la mitad del costo de la extensión por 14 semanas, es decir \$ 138.668 por madre (si las LEGHM1 siguen en $100 \%$ ), o un costo país de US\$ 18,8 millones anuales. Este costo podría ser incluso menor porque probablemente la distribución de LEGHM1 para niños menores de seis meses está más concentrada en períodos cercanos al final del posnatal de hoy en día. Lamentablemente no tenemos los datos para hacer un cálculo más fino.

- $\quad$ Extensión flexible: siete semanas de tiempo completo, 14 de tiempo parcial o cualquier combinación intermedia (cada una de las semanas de tiempo completo de la extensión puede canjearse por dos semanas de tiempo parcial). Como discutimos en el caso flexible con $100 \%$ de cobertura, en este caso calcular los costos es más difícil ya que no sabemos cómo tratar a las LEGHM1. Sin embargo, podemos suponer que los costos de esta política serían muy similares a los del caso inmediatamente anterior, es decir \$ 138.668 por madre (si las LEGHM1 siguen en $100 \%$ ) o un costo país de US\$18,8 millones anuales.

c) Pre y posnatal con $80 \%$ de cobertura (desde el principio)

- $\quad$ Extensión de 14 semanas (desde las 12 actuales hasta 26 semanas o seis meses): si suponemos que las LEGHM1 se siguen pagando al $100 \%$, el costo sería de $772.044 * 0,8-340.300=$ \$277.335. Pero consideremos también que el Estado está ahorrando un $20 \%$ en los días de licencia previos a la extensión (que en 2007 fueron 115 días en promedio por madre cotizante). Es decir, el Estado está ahorrando alrededor de $\$ 78,78 * 0,2 * 115=$ $\$ 181.194$. Eso da un costo aproximado por madre de \$ 96.141 o un costo país de US\$ 13 millones anuales.

- Extensión de siete semanas (desde las 12 actuales hasta 19, o un poco menos de cuatro meses y medio): el costo debería ser aproximadamente la mitad del costo de la extensión por 14 semanas, es decir \$ 48.071 por madre (si las LEGHM1 siguen en $100 \%$ ) o un costo país de US\$ 6,5 millones anuales. Este costo podría ser incluso menor porque probablemente la distribución 
de LEGHM1 para niños menores de seis meses está más concentrada en períodos cercanos al final del posnatal de hoy en día. No contamos con los datos, lamentablemente, para hacer un cálculo más fino.

- Extensión flexible: siete semanas de tiempo completo, 14 de tiempo parcial o cualquier combinación intermedia (cada una de las semanas de tiempo completo de la extensión puede canjearse por dos semanas de tiempo parcial). Podemos suponer que los costos de esta política serían muy similares a los del caso inmediatamente anterior, es decir \$ 48.071 por madre (si las LEGHM1 siguen en $100 \%$ ) o un costo país de US\$ 6,5 millones anuales.

d) Política mixta con disminución de cobertura de las licencias y de las LEGHM1

Si disminuimos el subsidio para las LEGHM1 al 80\% del salario materno tenemos varios beneficios:

- $\quad$ Primero que nada, cae el incentivo a usar licencias fraudulentas. Las madres enfrentarán un costo por no trabajar, aunque ese costo no será demasiado alto y por lo tanto no perjudicará mayormente a aquellas cuyos hijos sí estén gravemente enfermos.

- De los 63 días por niño que representaron las LEGHM1 en 2006, alrededor de 22 días son pedidos para niños mayores de seis meses. El ahorro que al Estado le significa bajar las coberturas de las LEGHM1 podría traspasarse para financiar una extensión del posnatal.

Un estudio preliminar del costo de la política mixta de extender el posnatal hasta las 22 o 26 semanas de tiempo completo y dejarlo todo (pre y posnatal y subsidio por LEGHM1) en cobertura $80 \%$ se presenta a continuación.

i) Costos, por mujer, de extensión del posnatal hasta las 26 semanas.

La política que estamos evaluando tiene dos ejes: por un lado, baja el porcentaje de cobertura por concepto de LEGHM1 y de permisos de pre y posnatal. Por otro lado, aumenta la duración de estos 
permisos. Para facilitar los cálculos, se evaluará el proyecto suponiendo que la extensión no es flexible (o alternativa rígida). El hecho de que el permiso se pueda tomar de manera flexible reduce los costos respecto de la alternativa rígida por dos razones:

- $\quad$ Pagar el 80\% del sueldo por una semana tiene un costo idéntico que pagar el $40 \%$ del sueldo por dos.

- $\quad$ Las madres que quieran usar el beneficio de las LEGHM1 sólo podrán hacerlo después de haber agotado su número de semanas de permiso, lo que significa que ninguna madre podrá usar el permiso antes de que su hijo cumpla 26 semanas. Sin embargo, como muchas madres querrán extender el permiso más allá aun, la flexibilidad de la política sólo contribuye a disminuir el uso de las LEGHM1.

Como la alternativa flexible es muy difícil de evaluar a priori, evaluaremos la alternativa rígida y usaremos los resultados de esa evaluación como cota superior para el costo de un proyecto en el que eventualmente se incluyera algún grado de flexibilidad en el uso del tiempo del permiso.

- $\quad$ Costo por concepto de pre y posnatal:

Pre y posnatales antes costaban $\$ 905.960$ por niño. Ahora que tenemos 14 semanas más costarán $\$ 905.960 * 0,8+14 * 7 * 78,78$ $* 0,8=724.768+617.635=\$ 1.342 .403$.

- $\quad$ Costo por concepto LEGHM1:

Una extensión del posnatal a 26 semanas implica que, como actualmente 41 de esos días son tomados por madres de niños menores de seis meses, ese gasto desaparecerá por completo ${ }^{35}$. Sólo quedan alrededor de 22 días por financiar, y éstos se financian con cobertura de sólo el $80 \%$. Es decir, el costo por concepto de LEGHM1 es ahora (por madre) de $22 * 0,8 * 8.300=\$ 146.080$.

35 Se podría argumentar que la mayor densidad de madres tomando LEGHM1 a fines del postnatal se "trasladaría” con la nueva política al nuevo final del posnatal. Eso aumentaría los costos. Sin embargo, el hecho de que la cobertura ahora sea de $80 \%$ limitará significativamente el incentivo a fraude y, además, no estamos considerando que alguna proporción significativa de las madres se tomará un posnatal que vaya más allá de los seis meses, lo que implica que los días de LEGHM1 usados en el cálculo estarían sobrestimados. En ese sentido, se considera que 22 días de LEGHM1 es una estimación relativamente conservadora. 
- $\quad$ Costo total del nuevo modelo:

Las anteriores estimaciones nos llevan a que en el nuevo esquema cada niño costará alrededor de $\$ 1.342 .403+\$ 146.080=$ $\$ 1.488 .483$.

ii) Costos, por mujer, de extensión del posnatal hasta las 22 semanas.

Nuevamente se evaluará el proyecto suponiendo que la extensión no es flexible (o alternativa rígida). Como discutimos anteriormente, el hecho de que el permiso se pueda tomar de manera flexible reduce los costos respecto de la alternativa rígida, por lo que los resultados de esta evaluación corresponden a una cota superior para el costo de un proyecto que incluya flexibilidad.

- $\quad$ Costo por concepto de pre y posnatal:

Los pre y posnatales antes costaban \$ 905.960 por niño. Ahora que tenemos 10 semanas más costarán $\$ 905.960 * 0,8+10 * 7 *$ $7.878 * 0,8=724.768+441.168=\$ 1.165 .936$.

- $\quad$ Costo por concepto LEGHM1:

Una extensión del posnatal a 22 semanas implica que el número de días de LEGHM1 va a ser entre los 22 días de la propuesta anterior y los 63 actuales. Sabemos que actualmente 41 de esos días son tomados por madres de niños menores de seis meses (o alrededor de 26 semanas). Si suponemos que esos 41 días se distribuyen uniformemente ${ }^{36}$ entre la semana 12 y la semana 26, entonces podemos asumir que una extensión a 22 semanas nos va a ahorrar alrededor de 29 días de LEGHM1 ${ }^{37}$. Sólo quedan unos 34 días por financiar, y éstos se financian con cobertura de sólo el 80\%. Es decir, el costo por concepto de LEGHM1 es ahora (por madre) de $34 * 0,8 * 8.300=\$ 225.760$.

${ }^{36}$ Supuesto conservador, ya que es conocido que la distribución de las LEGHM1 tiene mayor densidad mientras menor es el niño.

${ }^{37}$ Se podría argumentar que la mayor densidad de madres tomando LEGHM1 a fines del posnatal se "trasladaría" con la nueva política al nuevo final del posnatal. Eso aumentaría los costos. Sin embargo, el hecho de que la cobertura ahora sea de $80 \%$ limitará significativamente el incentivo a fraude y, además, no estamos considerando que alguna proporción significativa de las madres se tomará un posnatal que vaya más allá de los seis meses, lo que implica que los días de LEGHM1 usados en el cálculo estarían sobrestimados. En ese sentido, se considera que 34 días de LEGHM1 es una estimación relativamente conservadora. 
- $\quad$ Costo total del nuevo modelo:

Las anteriores estimaciones nos llevan a que en el nuevo esquema cada niño costará alrededor de $\$ 1.165 .936+\$ 225.760=$ $\$ 1.391 .696$.

iii) Comparación del costo por mujer con la nueva política versus el costo por mujer del esquema actual.

Como vimos al principio de este análisis, el costo por mujer de la política maternal vigente hoy en día es de alrededor de \$ 1.337.704. Por lo tanto, la extensión mixta del posnatal recién evaluada le costaría al gobierno \$ 53.992 por mujer (o un costo país de US\$ 7,3 millones anuales) en el caso de extender el permiso a 22 semanas, y \$ 96.787 por mujer (o un costo país de US\$13,1 millones anuales) si se lo extiende a 26 semanas (seis meses). Estos costos son más bien cotas superiores, ya que en el análisis no se ha considerado una serie de ahorros importantes que acarrearía esta política: ahorros en salud infantil derivados de un mayor nivel de lactancia materna y de menor exposición del niño a contagios en salas cuna, y ahorros en el costo de salas cuna, entre otros.

¿Cómo financiar las propuestas de extensión del posnatal asegurándonos que no signifique mayores costos para el país?

Aun cuando por las consideraciones recién mencionadas es muy probable que el costo efectivo de la propuesta d) ya esté bastante cercano a cero, la viabilidad política de bajar la cobertura tanto de las licencias maternales como de las LEGHM1 no es evidente. Por ello, aquí se proponen algunas ideas que podrían contribuir a disminuir incluso más los costos de las propuestas más caras, como a) y b). La principal de éstas es la de disminuir el tope máximo de bonificación. Hoy en día las madres que ganan menos de 60 UF mensuales reciben su sueldo completo cuando están con permiso. Ese tope es alto: \$1.260.000 a marzo del 2009. Bajar ese tope afectaría sólo a las mujeres con salarios muy altos, pero beneficiaría a la gran mayoría de las trabajadoras al liberar recursos gubernamentales que podrían ser utilizados para financiar las reformas mencionadas más arriba. Lamentablemente no tenemos datos desagregados de los pagos de licencia, 
por lo que no nos es posible estimar el impacto de esta baja en el tope, ni tampoco calcular cuál es el valor óptimo de éste.

También se puede diseñar una política que desincentive aun más el uso fraudulento de licencias por enfermedad del hijo menor de un año ${ }^{38}$, por ejemplo, instaurar una carencia para obtener acceso a este beneficio, o explicitar de manera más ajustada el tipo de enfermedades que efectivamente son graves.

\section{Algunas precisiones adicionales}

Los cálculos previos no incluyen el costo de una política solidaria que entregase un posnatal a las mujeres trabajadoras informales o independientes sin sus cotizaciones al día. Una posibilidad para esto es establecer el posnatal solidario para mujeres del $40 \%$ más pobre del país, que consista en un pago equivalente al costo del servicio de sala cuna de su hijo por un período similar o levemente inferior al del posnatal de las cotizantes. La mayor parte de estos costos se financiaría con el ahorro que el Estado haría por concepto de servicios de salas cuna para estos niños. Sin embargo, los pagos correspondientes a las primeras doce semanas de posnatal tendrían algún costo adicional ${ }^{39}$.

Una idea interesante es entregar flexibilidad al sistema para que los padres puedan compartir el posnatal con las madres. Ya que en Chile los hombres tienen salarios superiores que sus parejas, esta fuente de flexibilidad tendrá un costo adicional. Ese costo no debiera ser demasiado importante, sin embargo, ya que la experiencia internacional nos dice que en general son pocos los padres que hacen uso de esta posibilidad.

Las dos ideas recién expuestas tienen que ser considerablemente afinadas para formar parte de una propuesta. Es importante establecer una manera a través de la cual una mujer trabajadora no cotizante pueda demostrar su condición ocupacional para acceder al beneficio de posnatal solidario. Un mal diseño del mecanismo en cuestión puede llevar a abusos importantes del sistema por parte de madres inactivas. esta idea.

38 Agradezco a Fernando Coloma, Rossana Costa y María Paz Lagos por sugerir

${ }^{39}$ El servicio de salas cuna, tal y como está pensado por el programa Chile Crece Contigo, comienza cuando el niño tiene doce semanas de vida 
Por otro lado, la extensión del posnatal a los hombres es una idea bastante extendida en países desarrollados. Sin embargo, no está claro que en nuestro país una iniciativa de ese tipo no traiga consigo una enorme presión por parte de los trabajadores para acceder a derechos de fuero, los cuales se prestan para posteriores abusos ${ }^{40}$.

\subsubsection{Costos de las salas cuna}

El costo de la sala cuna, tal y como está pensada hoy en día, es de más de $\$ 120.000$ (pesos de 2007) mensuales por niño ${ }^{41}$. Es muy probable que el costo real de una sala cuna de calidad sea superior a esa cifra. Ello implica que el proyecto de sala cuna, durante el período de estudio relevante (entre las doce semanas y los seis meses del niño), tiene un costo de más de $\$ 384.000$.

\subsubsection{Comparación entre ambos proyectos}

Un niño que nace en el nivel $40 \%$ más pobre de la población y tiene una madre que trabaja le cuesta al país, entre las 12 y las 26 semanas de vida, más de \$384.000. Este gasto se da aun cuando esa madre ya recibió toda la ayuda asociada al permiso posnatal. Por lo tanto, al país le resulta más barato extender el posnatal de esa madre —menos de $\$ 96.787$ si consideramos el esquema de la alternativa d) ${ }^{42}$ y menos de \$277.335 si consideramos la alternativa b) — que financiar

40 Agradezco este comentario a Fernando Coloma, Rossana Costa y María Paz Lagos.

${ }^{41}$ Para tener una referencia del costo de jardines infantiles ver Dipres (2008). El informe habla de que la Junji aportaría a los jardines de administración delegada una suma de \$ 84.659 (de 2007) por niño de sala cuna por mes. Integra entregaría una cantidad menor, pero sus jardines asociados no alcanzarían a costear los estándares mínimos de servicio (de calificación y número de personal). El informe también establece que los costos para los jardines administrados por Junji son un $70 \%$ superiores a los costos de los jardines de administración delegada (estos últimos jardines suplen el déficit mediante donaciones, cobros a los padres u otros medios). Por eso, \$ 120.000 mensuales parece una cota inferior razonable sobre todo si se pretende entregar un servicio completamente gratuito y de relativa calidad.

${ }^{42}$ La cifra de \$ 96.787 corresponde al costo incremental promedio por mujer de extender el posnatal. Las madres del $40 \%$ de menores ingresos, que tienen derecho a salas cuna financiadas por el Estado, tienen sueldos inferiores al promedio, por lo que representan un costo incremental mucho menor. 
la asistencia a salas cuna de ese niño. Es cierto que muchas de esas madres no tienen trabajos formales, por lo que las políticas son poco comparables. Sin embargo, se puede proponer que las madres del $40 \%$ más pobre de la población que trabajan en el mercado informal o estudian reciban un posnatal solidario de un monto equivalente al costo que el gobierno debiera desembolsar por esos niños por concepto de esos meses de salas cuna.

Las comparaciones de costos entre los dos proyectos no son fáciles ya que los grupos objetivos son distintos. Es preciso establecer con claridad los alcances de cada proyecto para hacer una evaluación de costos exhaustiva; sin embargo, las cifras aquí presentadas contienen un orden de magnitud de los costos involucrados y, a primera vista, ambos parecen alcanzables desde un punto de vista presupuestario, e incluso el proyecto de extensión del posnatal podría tener ventajas de costos especialmente en el segmento más pobre de la población.

\section{CONCLUSIONES}

A partir del conocimiento expuesto en este artículo podemos presentar una serie de conclusiones respecto a la política óptima de apoyo a la maternidad y al niño menor de un año.

La evidencia es bastante robusta en establecer que el mercado laboral no debiera reaccionar negativamente a un aumento moderado del posnatal (hasta los seis meses). Aunque es posible que sí haya alguna disminución salarial para las mujeres, en general la evidencia apunta a que estos efectos no son demasiado importantes. Por otro lado, la oferta laboral femenina debiera aumentar y la demanda debiera mantenerse relativamente estable, en la medida en que los empleadores no vean incrementados los costos inherentes a la contratación de mujeres. Por lo tanto, no sería extraño que frente a una reforma de esta naturaleza nos encontremos con un incremento en la participación femenina en el mercado del trabajo.

Por otro lado, un posnatal más largo va a tener efectos positivos en la salud física y mental tanto de la madre como del niño. Como se vio a lo largo del artículo, cuando la madre pasa más tiempo con su hijo durante el primer año hay una serie de beneficios en el desarrollo infantil que permiten al niño construir una base sólida de seguridad sobre la cual construirá a futuro su personalidad y sus capacidades productivas. 
Al mismo tiempo, está bastante claro que la asistencia a salas cuna no es recomendable al menos como política país prioritaria. La evidencia muestra que la opción de que el niño permanezca con su madre es la mejor desde todo punto de vista. En ese sentido, y considerando que hay niños que nacen en desventaja cuando lo hacen en ambientes disfuncionales, que son en general más prevalentes en los estratos socioeconómicos bajos, es razonable pensar en políticas que apunten a la intervención de estas familias y apoyo a las madres que están en dificultades. Sin embargo, esas políticas no debieran considerar separar a la madre de su hijo mediante la institucionalización (diurna) de éste, sino que más bien debieran apoyar el fortalecimiento del vínculo entre ambos y apuntar a proveer a la madre las herramientas necesarias para que entregue el mejor cuidado posible al niño.

Aún más, es importante que la política pública apoye no sólo a las madres que han podido acceder a un empleo formal, sino que también debiese apuntar a ayudar a aquellas madres trabajadoras que no tienen sus cotizaciones al día. A estas madres, especialmente si pertenecen a los grupos más desposeídos, se les podría pagar el equivalente, o algo menos, del costo de la sala cuna del niño, exigiéndoles a cambio dedicación exclusiva al cuidado de éste.

Por último, nunca está de más cautelar que cualquier propuesta de extensión del posnatal debe ser realizada con mucho cuidado tomando en cuenta los costos y beneficios que una iniciativa de este tipo conllevaría. Debemos diseñar una política con un costo razonable para el Estado y que en lo posible no perjudique las condiciones de empleabilidad y salario de las mujeres, pero que al mismo tiempo cubra de manera apropiada sus necesidades y las del niño.

\section{BIBLIOGRAFÍA}

Aedo, (2002): “Evaluación Económica de la Prolongación del Posnatal. Informe Final”. Mimeo.

Albrecht, J. W., P. A. Edin, M. Sundström y S. B. Vroman (1999): “Career Interruptions and Subsequent Earnings: A Re-examination Using Swedish Data”. En Journal of Human Resources 34, pp. 294-311.

Anderson, P. y P. B. Levine (2000): “Child Care and Mothers’ Employment Decisions”. En D. E. Card y R. M. Blank (eds.), Finding Jobs: Work and Welfare Reform. New York: Russell Sage Foundation, pp. 420-462. 
Baker, Michael y Kevin Milligan (2005): "How Does Job-Protected Maternity Leave Affect Mothers’ Employment and Infant Health”. NBER Working Paper 11135, National Bureau of Economic Research.

(2008a): "Maternal Employment, Breastfeeding, and Health: Evidence from Maternity Leave Mandates”. NBER Working Paper 13826, National Bureau of Economic Research.

- (2008b): "Evidence from Maternity Leave Expansions of the Impact of Maternal Care on Early Child Development”. En Journal of Health Economics, Elsevier, Vol. 27 (4) julio, pp. 871-887.

Baker, Michael, Jonathan Gruber y Kevin Milligan (2008): "Universal Child Care, Maternal Labor Supply, and Family Well-Being”. En Journal of Political Economy, University of Chicago Press, Vol. 116 (4), pp. 709-745.

Barnett, W. S. (2008): "Preschool Education and its Lasting Effects: Research and Policy Implications”. Boulder and Tempe: Education and the Public Interest Center \& Education Policy Research Unit.

Barnett, W. S. y L. N. Masse (2007a): "Comparative Benefit-Cost Analysis of the Abecedarian Program and Policy Implications”. En Economics of Education Review 26(1), pp. 113-125.

(2007b): "Erratum to 'Comparative Benefit-Cost Analysis of the Abecedarian Program and Policy Implications””. En Economics of Education Review 26(3), pp. 395-396.

Baum, C. L. (2003): “The Effect of State Maternity Leave Legislation and the 1993 Family and Medical Leave Act on Employment and Wages”. En Labour Economics 10, pp. 573-596.

Becker, Gary y Kevin Murphy (1988): “The Family and the State”. En Journal of Law and Economics 31(1), pp. 1-18.

Bedregal, Paula (2006): “Intervenciones Efectivas. Revisión Sistemática de Estudios de Alta Calidad Metodológica”. En Banco Interamericano de Desarrollo, Estudio sobre Alternativas de Atención Integral a la Niñez Menor de 4 Años. Banco Interamericano de Desarrollo.

Belsky, Jay (2001): “Developmental Risks (Still) Associated with Early Child Care.” En $J$. Child Psychology and Psychiatry 42 (octubre), pp. 845-59.

- (2005): “Child Care and Its Impact on Young Children (0-2)”. En Encyclopedia of Early Childhood Development. Disponible en http://www.childencyclopedia.com/en-ca/home.html.

- (2008): "Quality, Quantity and Type of Child Care: Effects on Child Development in the USA". Occasional Paper 37. Liberales Institut.

Berger, L. M. y J. Waldfogel (2004): "Maternity Leave and the Employment of New Mothers in the United States". En Journal of Population Economics 17, pp. 331349.

Bernal, Raquel (2008): “The Effect of Maternal Employment and Child Care on Children's Cognitive Development”. En International Economic Review Vol. 49, 4 (noviembre), pp. 1173-1209.

Bernal, Raquel y Michael Keane (2009): “Child Care Choices and Children’s Cognitive Abilities: The Case of Single Mothers”. Mimeo.

Blau, D. M. (2000): “Child Care Subsidy Programs”. NBER Working Paper No 7806 (julio). 
Brooks-Gunn, J., W. Han y J. Waldfogel (2002): "Maternal Employment and Child Cognitive Outcomes in the First Three Years of Life: The NICHD Study of Early Child Care”. En Child Development 73, pp. 1052-1072.

Campbell, F. A. y C. Ramey (1995): "Cognitive and School Outcomes for High Risk African American Students at Middle Adolescence: Positive Effects of Early Intervention”. En American Educational Research Journal 32, pp. 743-772.

Case, Anne, Darren Lubotsky y Christina Paxson (2002): "Economic Status and Health in Childhood: The Origins of the Gradient”. En The American Economic Review Vol. 92, No 5 (diciembre), pp. 1308-1334, American Economic Association.

Chatterji, Pinka y Sara Markowitz (2004): "Does the Length of Maternity Leave Affect Maternal Health?” NBER Working Paper No 10206.

Chevalier, A. y T. K. Viitanen (2002): "The Causality Between Female Labour Force Participation and the Availability of Childcare”. En Applied Economics Letters Vol. 9, 14 (noviembre), pp. 915-918.

Clark, R., J. S. Hyde, M. J. Esser y M. H., Klein (1997): "Length of Maternity Leave and Quality of Mother-Infant Interactions”. En Child Development Vol. 68, N 2, pp. 364-383.

CLASP (2009): "Reinvesting in Child Care: State Infant/Toddler Policies”. Center for Law and Social Policy, disponible en http://www.clasp.org/ChildCareAndEarlyEducation/ ratios.pdf.

Cleveland, G. y M. Krashinsky (2003): Financing ECEC Services in OECD Countries. París: OECD.

Datta Gupta, N. y N. Smith (2002): “Children and Career Interruptions: The Family Gap in Denmark”. En Economica 69, pp. 609-629.

Decreto 177 (última modificación mediante el Decreto 181 de 2005). Disponible en www.bcn.cl/leyes/pdf/actualizado/10530.pdf . Biblioteca del Congreso Nacional.

Del Boca, Daniela, Silvia Pasqua y Chiara Pronzato (2009): "Motherhood and Market Work Decisions in Institutional Context: A European Perspective”. En Oxford Economic Papers 61, i147-i171.

Dettling, A., M. Gunnar y B. Donzella (1999): "Cortisol Levels of Young Children in Fullday Childcare Centers”. En Psychoneuroendocrinology 24, pp. 519-536.

Dirección de Presupuestos, Ministerio de Hacienda, Gobierno de Chile (2008): "Evaluación Comprehensiva del Gasto a la Subsecretaría de Educación (Programa de Educación Preescolar), Junta Nacional de Jardines Infantiles (JUNJI) y Fundación Integra”. Ministerio de Hacienda.

Dustmann, Christian y Uta Schönberg (2008): "The Effect of Expansions in Maternity Leave Coverage on Children's Long Term Outcomes”. IZA Discussion Paper $\mathrm{N}^{\circ} 3605$.

England, Paula y Nancy Folbre (1999): “Who Should Pay for the Kids?”. En The Annals of the American Academy of Political and Social Science 563(1), pp. 194-207.

Flores, Verónica (2009): Resumen Ejecutivo: Encuesta Barómetro Mujer y Trabajo 2008. Comunidad Mujer, Datavoz, OIT.

Gelbach, J. B. (2002): "Public Schooling for Young Children and Maternal Labor Supply”. En The American Economic Review Vol. 92, 1 (marzo), pp. 307-322.

Han, W., J. Waldfogel y J. Brooks-Gunn (2001): "The Effects of Early Maternal Employment on Later Cognitive and Behavioral Outcomes”. En Journal of Marriage and the Family 63, pp. 336-354. 
Hashimoto, M., R. Percy, T. Schoellner y B. A. Weinberg (2004): "The Long and Short of It: Maternity Leave Coverage and Women's Labor Market Outcomes”. En IZA Discussion Paper 1207.

Heckman, James y Masterov, Dimitriy (2007): “The Productivity Argument for Investing in Young Children”, IZA Discussion Paper N ${ }^{\circ}$ 2725, Institute for the Study of Labor (IZA).

Hoffman, L., L. M. Youngblade, R. L. Coley, A. S. Fuligni y D. D. Kovacs (1999): Mothers at Work: Effects on Children's Well Being. New York: Cambridge University Press.

Jacobson, Stephanie y Margerite Barratt (2000): “Overview: Child Care and Education”. Capítulo suplementario del Michigan Family Impact Seminar \# 1: Child Care and Education, disponible en http://www.familyimpactseminars.org/index.asp?p=1\& page $=$ seminar\&seminarid $=65 \&$ siteid $=23$.

James-Burdumy, Susanne, Mark Dynarski y John Deke (2008): “After School Program Effects on Behavior: Results from the 21st Century Community Learning Centers Program National Evaluation”. En Economic Inquiry 46 (enero), pp. 13-18.

Jaumotte, Florence (2003): "Labour Force Participation of Women: Empirical Evidence on the Role of Policy and Other Determinants in OECD Countries”. En OECD Economic Studies, № 37, 2003/2.

Jung (2001): “Gastroesophageal Reflux in Infants and Children”. En American Family Physician, diciembre.

Kamerman, Sheila (2000): "Parental Leave Policies: An Essential Ingredient in Early Childhood Education and Care Policies”. Society for Research in Child Development. Social Policy Report.

(2005): "Maternity, Paternity and Parental Leave Policies: The Potential Impacts on Children and their Families". En Encyclopedia on Early Childhood Development.

Klerman, J. y A. Leibowitz (1997): "Labor Supply Effects of State Maternity Leave Legislation”. En F. Blau y R. Ehrenberg (eds.), Gender and Family Issues in the Workplace. New York: Russel Sage, Press.

(1999): “Job Continuity Among New Mothers”. En Demography 36, pp. 145155.

Lalive, R. y J. Zweimüller (2005): "Does Parental Leave Affect Fertility and Return-toWork? Evidence from a True Natural Experiment”. En IZA Discussion Paper 1613, Institute for the Study of Labor (IZA).

Lefevre, Pierre y Philip Merrigan (2008): "The Effect of Child Care and Early Education Arrangements on Developmental Outcomes of Young Children”. En Canadian Public Policy 28 (junio), pp. 159-186.

Lindberg, Laura D. (1996): "Women's Decisions about Breastfeeding and Maternal Employment”. En Journal of Marriage and the Family 58(1), pp. 239-251.

Liu, Qian y Oskar Nördstrom (2009): “The Duration of Paid Parental Leave and Children’s Scholastic Performance”. En IZA Discussion Paper Nº 4244, IZA Institute for the Study of Labor.

Loeb, Susanna, Margaret Bridges, Daphna Bassok, Bruce Fuller y Russ Rumberger (2007): "How Much Is Too Much? The Influence of Preschool Centers on Children's Social and Cognitive Development”. En Economic Education Review 26 (febrero), pp. 52-66. 
Lucas, Robert (1988): “On the Mechanics of Economic Development”. En Journal of Monetary Economics 22, pp. 3-42.

Lundberg, Shelly y Robert Pollak (2007): “The American Family and Family Economics”. En Journal of Economic Perspectives, American Economic Association, 21(2), pp. 3-26.

McGovern, P., B. Dowd, D. Gjerdingen, I. Moscovice, L. Kochevar y B. Lohman (1997): "Time off Work and the Postpartum Health of Employed Women". En Medical Care Vol. $35 \mathrm{~N}^{\circ}$ 5, pp. 507-521.

Melhuish, Edward (2006): "Policy and Research on Preschool Care and Education in the UK”. En Early Childhood Care and Education. International Perspectives (Melhuish y Petrogiannis, eds). Routledge.

Melhuish, E., L. Quinn, K. Sylva, P. Sammons, I. Siraj-Blatchford, B. Taggart y G. Currie (2002a): Pre-school Experience and Social/behavioural Development at the Start of Primary School. Belfast, N. I.: Stranmillis University Press.

Melhuish, E., L. Quinn, K. Sylva, P. Sammons, I. Siraj-Blatchford, B. Taggart y C. Shields (2002b): Pre-school Experience and Cognitive Development at the Start of Primary School. Belfast, N. I.: Stranmillis University Press.

Melhuish, E. C., K. Sylva, P. Sammons, I. Siraj-Blatchford y B. Taggart (2001): “The Effective Provision of Pre-school Education Project”. Technical Paper 7: Social/ behavioural and Cognitive Development at 3-4 Years in Relation to Family Background. London: Institute of Education/DfES.

Ministerio del Trabajo y Previsión Social, Gobierno de Chile (2004): "Licencias Médicas por Enfermedad Grave de los Hijos. Asegurando un Gasto Fiscal Eficiente”. En Observatorio Laboral N ${ }^{\circ} 15$.

NICHD-ECCRN (National Institute of Child Health and Development / Early Childcare Research Network) (2003): "Does Amount of Time Spent in Childcare Predict Socioemotional Adjustment during the Transition to Kindergarten?”. En Child Development 74 (julio/agosto), pp. 976-1005.

(2004): "Multiple Pathways to Early Academic Achievement”. En Harvard Educ. Rev. 74 (primavera), pp. 1-29.

Nielsen, H. S., M. Simonsen y M. Verner (2004): "Does the Gap in Family Friendly Policies Drive the Family Gap?”. En Scandinavian Journal of Economics, Vol. 106(4), pp. 721-774, Blackwell Publishing.

OECD (2004): "Early Childhood Education and Care Policy Canada Country Note". Disponible en www.oecd.org/dataoecd/42/34/33850725.pdf.

- (2006): "Starting Strong II: Early Childhood Education and Care". OECD Publishing.

OMS (2000): “Health Aspects of Maternity Leave and Maternity Protection”. Statement to the International Labor Conference, June 2, 2000. Disponible en http:// www.who.int/reproductive-health/publications/maternal_mortality_2000/ Health_aspects_of_maternity_leave.en.html.

Ondrich, J., C. K. Spiess, Q. Yang y G. G. Wagner (1999): "Full Time or Part Time? Parental Leave Policy and the Return to Work after Childbirth in Germany”. En Research in Labor Economics 18, pp. 41-74.

Pylkkanen, Elina y Nina Smith (2004): "The Impact of Family-Friendly Policies in Denmark and Sweden on Mothers' Career Interruptions Due to Childbirth”. En IZA Discussion Paper N ${ }^{\circ}$ 1050, marzo, Institute for the Study of Labor. 
Ramey, C. T., F. A., Campbell, M. R. Burchinal, D. M. Bryant, B. H. Wasik, M. L. Skinner y D. M. Gardner (1999): Early Learning, Later Success: The Abecedarian Study. Chapel Hill, NC: Frank Porter Graham Child Development Institute.

Ray, Rebecca (2008): A Detailed Look at Parental Leave Policies in 21 OECD Countries. CEPR. Center for Economic and Policy Research.

Ruhm, Christopher J. (1998): "The Economic Consequences of Parental Leave Mandates: Lessons from Europe”. En Quarterly Journal of Economics 113(1), pp. 285-317. (2000a): "Parental Leave and Child Health". En Journal of Health Economics 19(6), pp. 931-960.

(2000b): "Parental Employment and Child Cognitive Development”. Working Paper N7666, National Bureau of Economic Research, Cambridge MA.

(2004): "Parental Employment and Child Cognitive Development”. En J. Human Resources 39 (invierno), pp. 155-192.

Schönberg, Uta y Johannes Ludsteck (2007): “Maternity Leave Legislation, Female Labor Supply, and the Family Wage Gap”. IZA Discussion Papers 2699, Institute for the Study of Labor (IZA).

Smolensky, Eugene y Jennifer Appleton Gootman, eds. (2003): Working Families and Growing Kids: Caring for Children and Adolescents. Committee on Family and Work Policies, National Research Council (U.S.). Washington: National Academies Press.

Spiess, C. Katharina y Katharina Wrohlich (2006): “The Parental Leave Benefit Reform in Germany: Costs and Labour Market Outcomes of Moving Towards the Scandinavian Model”. IZA Discussion Paper No 2372 (octubre).

Subsecretaría de Previsión Social, Gobierno de Chile (2006): "Encuesta de Protección Social”. Disponible en www.proteccionsocial.cl.

Superintendencia de Salud, Gobierno de Chile (2006): Boletín Estadístico.

Sylva, K., E. Melhuish, P. Sammons, I. Siraj-Blatchford y B. Taggart (2004): Effective Preschool Provision. London: Institute of Education.

Tanaka, Sakiko (2005): "Parental Leave and Child Health Across OECD Countries". En Economic Journal Vol. 115 № 501.

Ten Cate, Adrienne (2000): "Labor Market Effects of Maternity and Parental Leave Policy in Canada (2)”. Mimeo, McMaster University.

(2003): "The Impact of Provincial Maternity and Parental Leave Policies on Employment Rates of Women with Young Children in Canada”. Department of Economics Working Papers 2003-03, McMaster University.

Tokman, Marcelo, Jorge Rodríguez y Fernando Larraín (2004): “Subsidios por Incapacidad Laboral 1991-2002: Incentivos Institucionales, Crecimiento del Gasto y una Propuesta de Racionalización”. En Estudios Públicos 93 (verano).

Unicef (2008): "The Child Care Transition. A Leage Table of Early Childhood Education and Care in Economically Advanced Countries”. Innocenti Report Card 8. Innocenti Research Centre.

Vandell, D. L., J. S. Hyde, E. A. Plant y M. J. Essex (1997): "Fathers and Others as Infant Care Providers: Predictors of Parents' Emotional Well Being and Marital Satisfaction”. En Merrill Palmer Quarterly 43(3), pp. 361-385.

Waldfogel, Jane (2006): What Children Need. Harvard University Press. (1998a): "Understanding the Family Gap in Pay form Women with Children”. En Journal of Economic Perspectives 12, pp. 137-156. 
(1998b): "The Family Gap for Young Women in the United States and Britain: Can Maternity Leave Make a Difference?”. En Journal of Labor Economics 16(3), pp. 505-545.

Waldfogel, J., W.-J. Han y J. Brooks-Gunn (2002): "The Effects of Early Maternal Employment on Child Cognitive Development”. En Demography 39(2), pp. 369392.

Waldfogel, Jane, Y. Higuchi y M. Abe (1999): "Family Leave Policies and Women's Retention after Childbirth: Evidence from the United States, Britain and Japan”. En Journal of Population Economics 12(4), pp. 423-546.

Watamura, S. E., B. Donzella, J. Alwin, y M. R. Gunnar (2003): “Morning to Afternoon Increases in Cortisol Concentrations for Infants and Toddlers at Child Care: Age Differences and Behavioral Correlates”. En Child Development 74(4), pp. 10061020.

Winegarden, C. R. y Paula M. Bracy (1995): "Demographic Consequences of MaternalLeave Programs in Industrial Countries: Evidence from Fixed-Effects Models”. En Southern Economic Journal 61, pp. 1020-1035.

Zveglich, J. E. y Y. Rodgers (2003): "The Impact of Protective Measures for Female Workers”. En Journal of Labor Economics 21 (3). 